Universidade de São Paulo

Instituto de Física de São Carlos

POLIANA HEIFFIG PENTEADO

Modelo de Heisenberg antiferromagnético com interações não-uniformes

São Carlos 

POLIANA HEIFFIG PENTEADO

\section{Modelo de Heisenberg Antiferromagnético com interações não-uniformes}

Dissertação apresentada ao Programa de PósGraduação em Física do Instituto de Física de São Carlos da Universidade de São Paulo para obtenção do título de Mestre em Ciências.

Área de concentração: Física Básica.

Orientador: Prof. Dr. Valter Luiz Líbero.

São Carlos

2008 
AUTORIZO A REPRODUÇÃO E DIVULGAÇÃO TOTAL OU PARCIAL DESTE TRABALHO, POR QUALQUER MEIO CONVENCIONAL OU ELETRÔNICO, PARA FINS DE ESTUdo E PESQUiSA, DESDE QUE CITADA A FONTE.

Ficha catalográfica elaborada pelo Serviço de Biblioteca e Informação IFSC/USP

\section{Penteado, Poliana Heiffig}

Modelo de Heisenberg antiferromagnético com interações não-uniformes / Poliana Heiffig Penteado; orientador Valter Luiz Libero.-- São Carlos, 2008.

$81 \mathrm{p}$.

Dissertação (Mestrado - Programa de Pós-Graduação em Física - Área de concentração: Física Básica) - Instituto de Física de São Carlos da Universidade de São Paulo.

1. Física da matéria condensada. 2. Modelo de Heisenberg. 3. Teoria do funcional da densidade. 4. Cadeia alternada I.Título. 


\section{FOLHA DE APROVAÇÃO}

Poliana Heiffig Penteado

Dissertação apresentada ao Instituto de Física de São Carlos da Universidade de São Paulo para obtenção do título de Mestre em Ciências. Área de Concentração: Física Básica.

Aprovada em: 25/07/2008

\section{Comissão Julgadora}

Prof. Dr. Valter Luiz Libero

Instituição: IFSC/USP

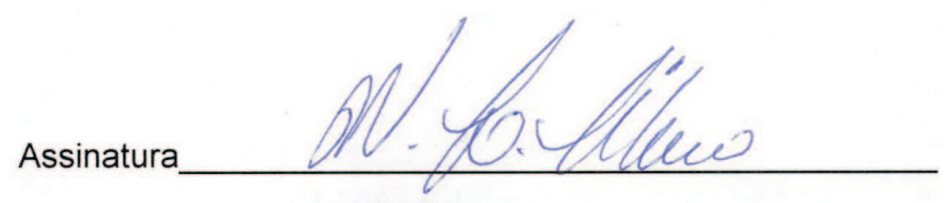

Prof. Dr. Antonio Jose Roque da Silva Instituição: IF/USP

Prof. Dr. Jose Candido Xavier Instituição: UFU

Assinatura
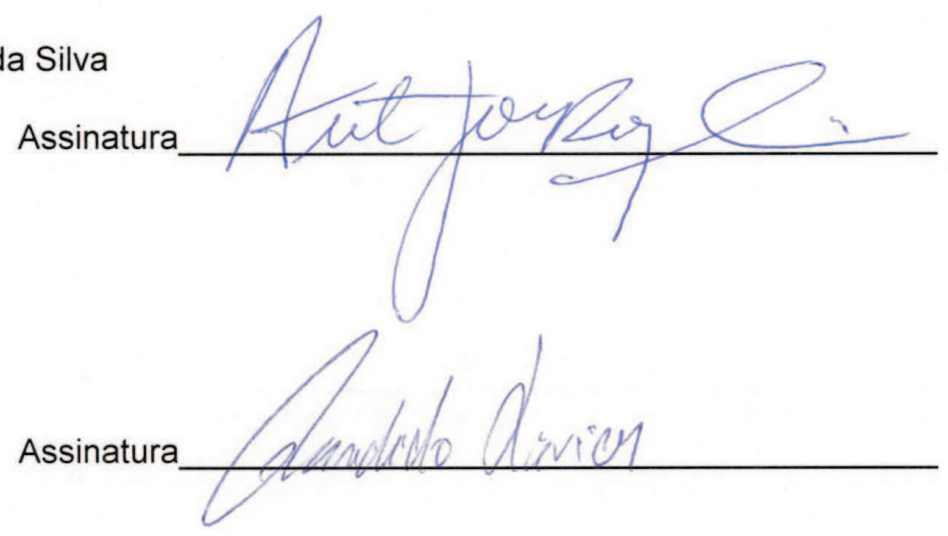



\section{DEDICATÓRIA}

Dedico este trabalho aos meus pais, Paulo e Stella, e à minha irmã Juliana, pelo carinho, compreensão, apoio e paciência. 



\section{AGRADECIMENTOS}

Ao Prof. Valter Líbero, meu orientador desde a graduação, pela ajuda e incentivos constantes, pela grande contribuição na minha formação e pela paciência ao compreender minhas falhas.

Aos demais professores do IFSC, em especial ao Prof. Klaus Capelle, pelas discussões durante o desenvolvimento do projeto de iniciação científica.

A todos os funcionários do IFSC.

À minha família pela dedicação, cumplicidade e apoio constantes.

Aos meus amigos e colegas de faculdade Afonso, Jonathas, Mariana, Marcos Felipe, Guilherme (Blane), Adriano, Gerson, Carlos Brasil e Victória. Em especial ao Fabiano que esteve sempre disposto a ajudar, fazendo a revisão literária e dando apoio até o fim.

À amiga Aline pelo companheirismo e amizade sincera.

À amiga Carina pela amizade e que, mesmo à distância sempre me incentivou.

À amiga Alessandra, pela amizade e pelos momentos de descontração.

À FAPESP, pelo auxílio financeiro. 

A coisa mais bela que o homem pode experimentar é o mistério. É esta a emoção fundamental que está na raiz de toda ciência e arte. O homem que desconhece esse encanto, incapaz de sentir admiração e estupefação, esse já está, por assim dizer, morto e tem os olhos extintos.

Albert Einstein 



\section{RESUMO}

\section{PENTEADO, P. H. Modelo de Heisenberg antiferromagnético com interações}

não-uniformes. 2008. (79) p. Dissertação (Mestrado) - Instituto de Física de São Carlos, Universidade de São Paulo, São Carlos, 2008.

Nesta dissertação, estudamos cadeias unidimensionais antiferromagnéticas de spins 1/2 modeladas pelo Hamiltoniano de Heisenberg na presença de inomogeneidades causadas principalmente pela introdução de ligações substitucionais (defeitos nas ligações) e por efeitos de borda. Interessados então em determinar a energia do estado fundamental de sistemas com quaisquer distribuições das ligações, utilizamos o formalismo da Teoria do Funcional da Densidade (DFT) desenvolvido para o modelo de Heisenberg. O formalismo da DFT permite a estimativa da energia do estado fundamental de sistemas não-homogêneos conhecendo-se o sistema homogêneo. Construímos funcionais na aproximação da ligação local (LBA), proposta recentemente em analogia à já conhecida LSA (aproximação local para o spin). A obtenção dos funcionais se baseou no estudo do modelo de uma cadeia de spins em que as ligações são alternadas, isto é, a interação de troca se alterna em valor de sítio para sítio. Isso originou um funcional não-local na interação de troca da cadeia. Apesar disso, continuamos utilizando a nomenclatura LBA. Todos os resultados fornecidos pelos funcionais são comparados a dados provenientes de diagonalização numérica exata.

Palavras-chave: Física da matéria condensada. Modelo de Heisenberg. Teoria do funcional da densidade. Cadeia alternada. 



\begin{abstract}
PENTEADO, P. H. Antiferromagnetic Heisenberg model applied to nonuniform interactions. 2008. (79) p. Thesis (Master) - Instituto de Física de São Carlos, Universidade de São Paulo, São Carlos, 2008.

In this dissertation, we use the Heisenberg model to describe inhomogeneous antiferromagnetic spin $1 / 2$ chains. The translational invariance is broken mainly due to the non-uniform distribution of bond interactions (defects) and the presence of boundaries. Interested in obtaining the ground-state energy of systems with any distribution of exchange couplings $\left(J_{i j}\right)$, we use the density-functional theory (DFT) formalism, developed for the Heisenberg model. The DFT formalism allows an estimate of the ground-state energy of inhomogeneous systems based on the homogeneous systems. We build functionals for the ground-state energy using a local bond approximation (LBA), recently proposed in analogy to the already known LSA (local spin approximation). To obtain the functionals we studied a model that describes an alternating chain, in which the exchange coupling alternates from site-to-site. This resulted in non-local functionals on the spin-spin exchange interaction. Nevertheless, we still call them LBA functionals. All the results from the functionals are compared with exact numerical data.
\end{abstract}

Keywords: Condensed matter physics. Heisenberg model. Density-functional theory. Alternating chain. 



\section{Lista de Figuras}

Figura 3.1 Cadeia com defeitos nas ligações. $\quad . \quad$. . . . . . . . . . . . . . . . . . . 37

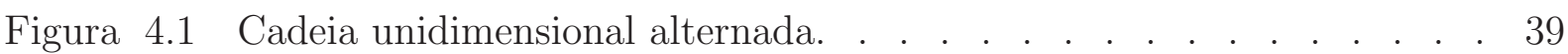

Figura 4.2 Comparação entre a energia do estado fundamental, por ligação, de uma cadeia de 24 spins 1/2 (condição de contorno periódica) com a série proposta na Ref. (11). . . . . . . . . . . . . . . . . . . . 42

Figura 4.3 Comparação entre a energia do estado fundamental, por ligação, de uma cadeia de 23 spins 1/2 (condição de contorno aberta) com a série proposta na Ref. (11). . . . . . . . . . . . . . . . . . . . . . 42

Figura 5.1 Configuração do estado fundamental de uma cadeia com $J>0$ (antiferromagnetismo) segundo campo médio. . . . . . . . . . . . . . 45

Figura 5.2 Cadeia alternada antiferromagnética, $J_{1}>0$ e $J_{2}>0 . . \quad$. . . . . . . 45

Figura 5.3 Ilustração de uma cadeia alternada com número de sítios par com condição de contorno periódica. . . . . . . . . . . . . . . . . . 45

Figura 5.4 Condição de contorno periódica - $L$ par. . . . . . . . . . . . . . . 46

Figura 5.5 Condição de contorno aberta - $L$ ímpar. . . . . . . . . . . . . . 46

Figura 5.6 Energia do estado fundamental de uma cadeia com $L=24$ sítios e ccp em função do parâmetro $\alpha$. Os dados numéricos são representados pelos quadrados em preto e o campo médio pelos círculos vermelhos. . 47

Figura 5.7 Energia do estado fundamental de uma cadeia com $L=23$ sítios e cca em função do parâmetro $\alpha$. Os dados numéricos são representados pelos quadrados pretos e o campo médio pelos círculos vermelhos. . 47 
Figura 5.8 Sistema homogêneo, referência para a construção da energia de correlação. . . . . . . . . . . . . . . . . . . . . . . . . . . . 49

Figura 6.1 Situação 1 - Cadeia alternada com um defeito $J^{\prime}$ no lugar de uma ligação $\alpha J$. . . . . . . . . . . . . . . . . . . . . . . . . . . . . 52

Figura 6.2 Situação 2 - Cadeia alternada com um defeito $J^{\prime}$ no lugar de uma ligação J. . . . . . . . . . . . . . . . . . . . . . . . . . . 53

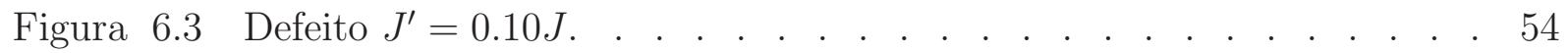

Figura 6.4 Defeito $J^{\prime}=0.90 J . \quad . \quad . \quad . \quad . \quad . \quad . \quad . \quad . \quad . \quad . \quad . \quad . \quad . \quad . \quad . \quad . \quad .54$

Figura 6.5 Cadeia uniforme com um defeito $J^{\prime} . \quad . \quad . \quad . \quad . \quad . \quad . \quad . \quad . \quad . \quad . \quad . \quad . \quad . \quad . \quad .54$

Figura 6.6 Energia do estado fundamental por ligação e em unidades de $J$ em função do defeito $J^{\prime}$. Os dados numericamente exatos são representados pelos quadrados pretos, LBA pelos triângulos azuis e campo médio pelos círculos vermelhos. Em (b) temos em escala ampliada os resultados exatos e o funcional. . . . . . . . . . . . . . . . . . 55

Figura 6.7 Energia do estado fundamental por ligação e em unidades de $J$ em função do defeito $J^{\prime}$ para condição de contorno aberta. Os dados obtidos por diagonalização exata são representados pelos quadrados pretos, LBA pelos triângulos azuis e campo médio pelos círculos vermelhos. Em (b) temos em escala ampliada os resultados exatos e o funcional. . 55

Figura 6.8 Caso 1 - cadeia com três defeitos sendo que dois deles substituem

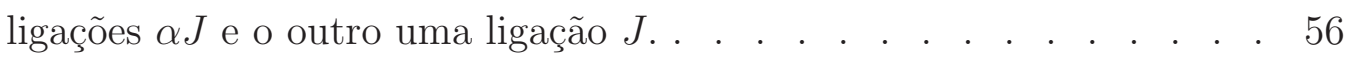

Figura 6.9 Caso 2 - Cadeia com três defeitos sendo que dois deles substituem ligações $J$ e o outro uma ligação $\alpha J$. . . . . . . . . . . . . . . 57

Figura 6.10 Caso 1. . . . . . . . . . . . . . . . . . . . . . . . . . . . 57

Figura 6.11 Caso 2. . . . . . . . . . . . . . . . . . . . . . . . . . . . 57

Figura 6.12 Os quadrados em preto representam os dados obtidos por diagonalização exata, os triângulos em azul a LBA para um defeito em uma posição $\alpha J$ e os círculos em rosa a LBA para um defeito em uma

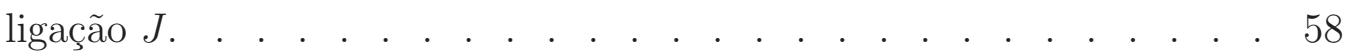


Figura 6.13 Energia de uma cadeia uniforme com um defeito $J^{\prime}=0.50 J$ em função da posição do defeito; à direita temos os dados numéricos exatos e o funcional em uma escala ampliada.. . . . . . . . . . . . . . . . . . . 59

Figura 6.14 Um defeito $J^{\prime}=5 J$ no interior da cadeia. . . . . . . . . . . . . . 60

Figura 6.15 Um defeito $J^{\prime}=5 J$ na borda. . . . . . . . . . . . . . . . . . . 61

Figura 7.1 Cadeia uniforme com defeitos ferromagnéticos. . . . . . . . . . . 63

Figura 7.2 Configuração do estado fundamental de uma cadeia uniforme, com $L$ par e condição de contorno periódica com um defeito ferromagnético $\left|J^{\prime}\right|<J$

Figura 7.3 Configuração do estado fundamental de uma cadeia uniforme, com $L$ par e condição de contorno periódica com um defeito ferromagnético para $\left|J^{\prime}\right|>J$

Figura 7.4 Energia de campo médio por ligação e em unidades de $J$ para uma cadeia uniforme com um defeito ferromagnético. Observe o alinhamento dos spins 2 e 3, apesar do sinal de $J^{\prime} / J$.

Figura 7.5 Energia do estado fundamental por ligação e em unidades de $J$ para uma cadeia uniforme com um defeito ferromagnético; à direita em escala ampliada.

Figura 7.6 Configuração de mínima energia para uma cadeia com dois defeitos ferromagnéticos..

Figura 7.7 Energia do estado fundamental, por ligação e em unidades de $J$, em função da razão $J^{\prime} / J$ para uma cadeia uniforme com dois defeitos ferromagnéticos..

Figura 7.8 Sistema com ligações que se alternam entre antiferromagnéticas e ferromagnéticas, $\alpha<0$.

Figura 7.9 Energia do estado fundamental por ligação e em unidades de $J$ para uma cadeia em que as interações se alternam entre antiferromagnéticas e ferromagnéticas. . . . . . . . . . . . . . . . . . . . . . 67

Figura 7.10 Cadeia alternada com defeitos ferromagnéticos. . . . . . . . . . . 68 
Figura 7.11 Configuração que minimiza a energia de campo médio quando $\left|J^{\prime}\right|>$

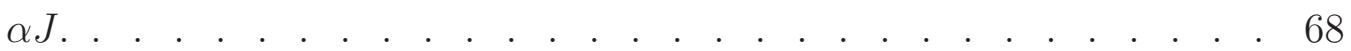

Figura 7.12 Configuração que minimiza a energia de campo médio quando $\left|J^{\prime}\right|<$

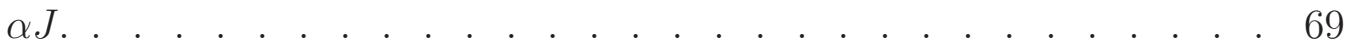

Figura 7.13 Energia do estado fundamental por ligação e em unidades de $J$ para uma cadeia alternada com um defeito ferromagnético substituindo uma ligação $\alpha J, J^{\prime}=-0.80 J$. . . . . . . . . . . . . . . . . . . . . 69

Figura 7.14 Sistema com ligações que se alternam entre ferromagnéticas e antiferromagnéticas. . . . . . . . . . . . . . . . . . . . . . 70

Figura 7.15 Energia do estado fundamental por ligação e em unidades de $J$ para uma cadeia em que as ligações se alternam entre ferromagnéticas e antiferromagnéticas. . . . . . . . . . . . . . . . . . . . . 71 


\section{Lista de Tabelas}

Tabela 5.1 Estimativa de memória e tempo de CPU para diferentes tamanhos de rede, $\alpha=0.5$ e cсp. . . . . . . . . . . . . . . . . . . . . . . . . . 48

Tabela 6.1 Caso 1. . . . . . . . . . . . . . . . . . . . . . . . . . . . 56

Tabela 6.2 Caso 2. . . . . . . . . . . . . . . . . . . . . . . . . . . . 56 



\section{Sumário}

1 Introdução 23

2 Modelo de Heisenberg $\quad 27$

3 Teoria do Funcional da Densidade $\quad 34$

4 Cadeia Alternada Antiferromagnética 38

4.1 O Modelo . . . . . . . . . . . . . . . . . . . . . . . 39

4.2 Motivação . . . . . . . . . . . . . . . . . . . . . . 41

5 Construção do Funcional $\quad 44$

5.1 Campo Médio . . . . . . . . . . . . . . . . . . . . . 44

5.2 Correlação . . . . . . . . . . . . . . . . . . . . . . . . 48

6 Defeitos Antiferromagnéticos $\quad 52$

6.1 Cadeia alternada com um defeito antiferromagnético . . . . . . . . . 52

6.2 Cadeia uniforme com um defeito antiferromagnético . . . . . . . . . . . . 54

6.2.1 Condição de Contorno Periódica . . . . . . . . . . . . . . . 54

6.2.2 Condição de Contorno Aberta . . . . . . . . . . . . . . . . . 55

6.3 Cadeias com vários defeitos . . . . . . . . . . . . . . 56

6.4 Relevância da posição dos defeitos na cadeia . . . . . . . . . . . . . . 58

6.5 Outros funcionais . . . . . . . . . . . . . . . . . . . . . 59

7 Defeitos Ferromagnéticos $\quad 62$

7.1 Cadeia uniforme com defeitos ferromagnéticos . . . . . . . . . . 63 
7.1.1 Número ímpar de defeitos . . . . . . . . . . . . . . . . . 63

7.1 .2 Número par de defeitos . . . . . . . . . . . . . . . . 65

7.2 Cadeia alternada com defeitos ferromagnéticos . . . . . . . . . . . 68

7.3 Cadeia com ligações alternando entre ferromagnéticas e antiferromagnéticas 70

8 Conclusões

Referências 76

Apêndice A 


\section{Capítulo 1}

\section{Introdução}

A palavra magnetismo e a idéia por ela expressa são de conhecimento popular. Os núcleos de transformadores e os eletroímãs são exemplos de aplicativos que põem em destaque as propriedades magnéticas de alguns materiais, em geral compostos por ferro. O tipo de magnetismo presente nessas substâncias é o ferromagnetismo e é apenas uma das várias manifestações encontradas na natureza. Essa forma de magnetismo, amplamente aplicada na indústria, só foi melhor compreendida com o surgimento da Mecânica Quântica, isso porque o ferromagnetismo, assim como o antiferromagnetismo e o paramagnetismo, se devem basicamente ao momento magnético intrínseco dos elétrons, o spin.

Os dois primeiros tipos de magnetismo são conseqüência da cooperação dos momentos magnéticos entre si, apresentando magnetização espontânea abaixo de uma determinada temperatura crítica. Dessa maneira, um modelo que seja capaz de explicar tal comportamento deve levar em conta a interação entre momentos magnéticos.

O modelo proposto por Heisenberg $(1,2)$ em 1926, foi um dos primeiros a considerar a interação entre spins como sendo responsável pelo magnetismo espontâneo, e ainda hoje, é bastante explorado no estudo das propriedades magnéticas dos materiais, sendo aplicado não só na Física como também na Química $(3,4)$. O Hamiltoniano que define o modelo, e que será objeto de estudo desta dissertação, é

$$
\hat{H}=\sum_{<i, j>} J_{i j} \hat{\mathbf{S}}_{\mathbf{i}} \cdot \hat{\mathbf{S}}_{\mathbf{j}}
$$


onde $\hat{S}_{i}$ é o operador de spin que atua no i-ésimo sítio e $J_{i j}$ é a interação de troca entre dois spins.

Embora cerca de oitenta anos tenham se passado desde a sua proposição, a solução analítica desse modelo só é conhecida para cadeias homogêneas, isto é, aquelas em que todos os sítios da rede são equivalentes, lineares e de spins 1/2 através do Ansatz de Bethe $(5,6)$. Para um spin $S$ qualquer temos soluções aproximadas, como por exemplo a obtida da teoria de Ondas de spin (Spin-wave) (7), ou as obtidas via o Grupo de Renormalização da Matriz Densidade (8). Tais soluções no entanto, se aplicam apenas a sistemas homogêneos. Essa limitação é restritiva, já que em problemas reais é comum encontrarmos inomogeneidades induzidas por exemplo, por campos magnéticos não-uniformes, efeitos de tamanho finito, impurezas (spins diferentes) e defeitos (ligações substitucionais).

Assim, a escassez de resultados para sistemas com quebra de simetria translacional motiva a busca por novas ferramentas que sejam aplicáveis a tais situações. Com esse intuito, nosso trabalho pretende utilizar o formalismo da Teoria do Funcional da Densidade desenvolvido recentemente para o Hamiltoniano de Heisenberg (9).

Inicialmente a DFT aplicada ao Hamiltoniano de Heisenberg foi explorada em sistemas em que a causa da quebra de simetria translacional se devia a impurezas (10). No presente trabalho vamos tratar de outra causa de inomogeneidade: ligações substitucionais, isto é, defeitos na rede.

Estamos interessados em determinar a energia do estado fundamental de cadeias antiferromagnéticas em que os defeitos possam ser tanto antiferromagnéticos quanto ferromagnéticos. No contexto da DFT, escrevemos a energia de uma cadeia de spins $1 / 2$ com ligações $J_{i j}$ como

$$
E=E^{C M}+E^{C}
$$

onde $E^{C M}$ é a energia calculada na aproximação de campo médio (termo conhecido) e $E^{C}$ é a chamada energia de correlação (termo desconhecido e que requer aproximações).

Para determinar $E^{C}$ vamos usar uma aproximação local, denominada Aproximação da Ligação Local (em inglês Local Bond Approximation - LBA) e construir um funcional das interações $J_{i j}$. Na construção do funcional precisamos de uma expressão da energia 
do estado fundamental de um sistema homogêneo $(E)$, que no nosso caso será uma cadeia alternada antiferromagnética (11), isto é, uma cadeia em que as interações se alternam entre dois valores $\left(J_{1}\right.$ e $\left.J_{2}\right)$. Homogêneo aqui entende-se a cadeia vista como constituída de dímeros com ligações $J_{1}$ e $J_{2}$. Dessa maneira, a nossa implementação consistirá em explorar a razão entre esses dois valores de interação e construir um funcional não-local nas interações $J_{i j}$, mas local na razão $\frac{J_{i+1}}{J_{i}}$.

Nos Capítulos 2 e 3 fazemos, respectivamente, uma introdução ao modelo de Heisenberg e à Teoria do Funcional da Densidade. Em seguida (Capítulo 4), exploramos os resultados para a cadeia alternada antiferromagnética utilizada como nosso sistema homogêneo. O Capítulo 5 refere-se à construção dos funcionais e à exploração dos limites de validade desses. Nos Capítulos 6 e 7 mostramos os resultados da aplicação dos funcionais a cadeias antiferromagnéticas contendo defeitos antiferromagnéticos e/ou ferromagnéticos.

A título de exemplo, ilustramos abaixo um dos resultados deste trabalho para uma cadeia uniforme (todos os sítios interagem com parâmetro de troca $J$ ) de spins $1 / 2$ e tamanho $L=24$, com condição de contorno periódica, em que substituímos uma das ligações $J$ por um defeito $0 \leq J^{\prime} \leq J$ (antiferromagnético). Os triângulos azuis representam a energia do estado fundamental por partícula e em unidades de $J$ em função da razão $\frac{J^{\prime}}{J}$ fornecida pelo nosso funcional, os quadrados em preto os dados numericamente exatos e os círculos vermelhos a aproximação de campo médio.

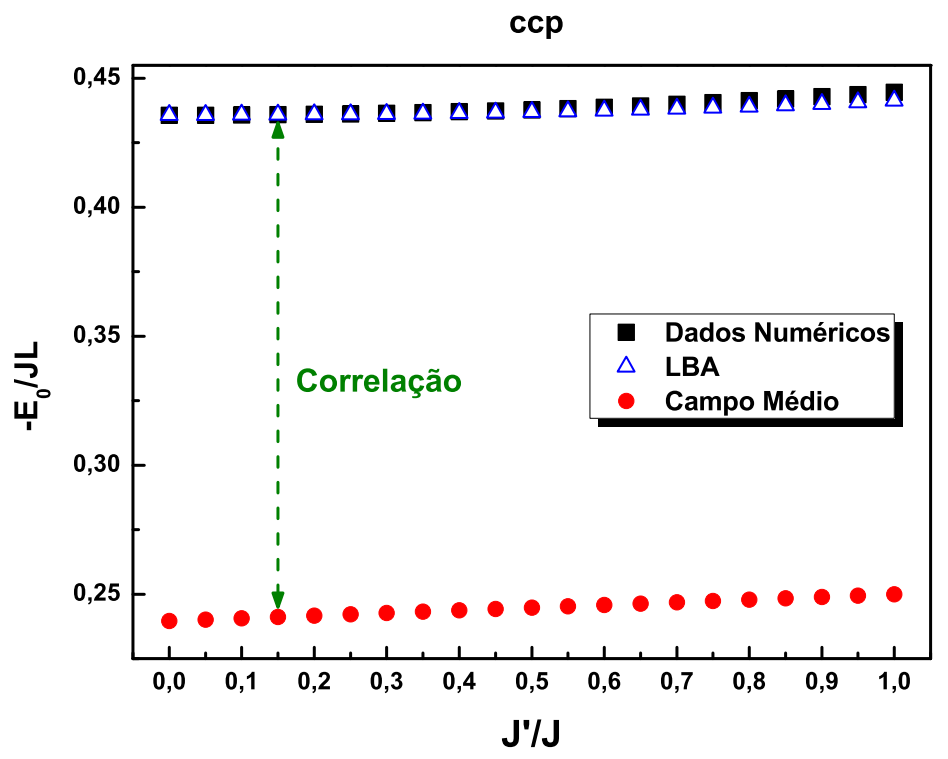


No gráfico acima podemos notar a visível melhora nos resultados obtidos com o funcional em relação àqueles fornecidos pela aproximação de campo médio. A boa concordância entre resultados numericamente exatos e funcional sugere que este último, construído utilizando-se uma aproximação local, é capaz de reproduzir bastante bem situações em que defeitos estão presentes. 


\section{Capítulo 2}

\section{Modelo de Heisenberg}

A maneira mais natural de classificar as propriedades magnéticas de um material é pela sua resposta a um campo magnético aplicado. Essa resposta é caracterizada pela susceptibilidade, $\chi$, na relação

$$
\vec{M}=\chi \vec{H}
$$

onde $\vec{M}$ é a magnetização, ou momento magnético por unidade de volume, e $\vec{H}$ é o campo aplicado.

Há, no entanto, alguns materiais contendo átomos magnéticos que exibem um momento magnético não-nulo abaixo de uma certa temperatura e na ausência de campo magnético externo. Essa propriedade é chamada de magnetização espontânea e decorre da interação entre os átomos magnéticos que tendem a alinhar seus momentos magnéticos.

O tipo mais simples de material magneticamente ordenado é o ferromagneto, no qual os momentos magnéticos dos átomos se alinham paralelamente e se somam para produzir um momento magnético macroscópico diferente de zero. Essa definição, entretanto, é válida abaixo de uma determinada temperatura crítica, conhecida como temperatura de Curie.

Os materiais ferromagnéticos são conhecidos há um longo tempo e têm aplicação tecnológica importante. Mais comuns, mas descobertos somente na década de 30, são os antiferromagnetos, nos quais os momentos magnéticos dos átomos se somam e resultam em um momento magnético macroscópico nulo. 
O fenômeno do antiferromagnetismo foi previsto por L. Néel em 1936. Na sua forma mais simples os materiais antiferromagnéticos podem ser considerados como constituídos de duas sub-redes equivalentes que se interpenetram, de maneira que cada uma delas possua um momento magnético médio não-nulo, mas com orientações opostas e com tal magnitude que se cancelam exatamente, sendo o momento magnético da rede nulo em qualquer temperatura. Essa descrição é verdadeira apenas abaixo de uma certa temperatura, denominada temperatura de Néel. Acima da temperatura de transição (crítica), onde os efeitos da agitação térmica predominam, nem ferromagnetos nem antiferromagnetos apresentam magnetização espontânea.

Para explicar a ordem magnética que se estabelece em tais materiais e a localização da temperatura crítica, é necessário um tratamento teórico que inclua um modelo que descreva as interações responsáveis pelo comportamento cooperativo entre os átomos e uma análise estatística apropriada a um sistema de muitos corpos sujeito a essas interações.

A primeira proposta de que magnetização espontânea era devido às interações entre os átomos magnéticos, foi feita por Pierre Weiss (12) em 1907. Todavia, as interações dipolares por ele imaginadas se mostraram muito pequenas $\left(\approx 10^{-4} \mathrm{eV}\right)$ para levar em conta as temperaturas de transição de materiais como ferro e cobalto. Somente com o nascimento da teoria quântica é que se mostrou que a origem das interações é na verdade eletrostática e surge como conseqüência da interação coulombiana entre elétrons e da restrição imposta à função de onda pelo princípio de exclusão de Pauli, segundo o qual, a função de onda eletrônica total deve ser anti-simétrica em relação à troca das coordenadas espaciais e de spin de um par de elétrons. Tal imposição faz com que as energias do sistema sejam dependentes da orientação dos spins.

Para mostrar a manifestação da mecânica quântica na natureza eletrostática da interação, vamos considerar um sistema simples composto por dois elétrons $(13,14)$. O Hamiltoniano que descreve esse sistema é dado por

$$
\hat{H}=-\frac{\hbar^{2}}{2 m} \nabla_{1}^{2}-\frac{\hbar^{2}}{2 m} \nabla_{2}^{2}+V(1)+V(2)+\frac{e^{2}}{r_{12}} \equiv \hat{H}_{0}+\hat{U}_{i n t},
$$

onde 1 e 2 indicam respectivamente as coordenadas espaciais dos elétrons, $V$ o potencial 
ao qual estão sujeitos, $r_{12}$ a separação entre eles e $\hat{U}_{i n t}=\frac{e^{2}}{r_{12}}$ é a interação elétron-elétron (coulombiana).

Quando desconsideramos a interação $\hat{U}_{i n t}$, o Hamiltoniano do problema, dado por

$$
\hat{H}_{0}=-\frac{\hbar^{2}}{2 m} \nabla_{1}^{2}+\hat{V}(1)-\frac{\hbar^{2}}{2 m} \nabla_{2}^{2}+\hat{V}(2)
$$

é separável (elétrons independentes) e a sua solução é

$$
E^{(0)}=E_{i}+E_{j}, \quad \Psi=\psi_{i}(1) \psi_{j}(2),
$$

com $\psi_{i}$ e $\psi_{j}$ soluções para o problema de um único elétron.

O efeito da interação $\hat{U}_{\text {int }}$ pode ser apreciado tratando-se o problema através de teoria de perturbação, muito embora via de regra esse termo corresponda a uma interação muito forte. A energia corrigida até primeira ordem é escrita como

$$
E=E^{(0)}+\int \psi_{i}^{*}(1) \psi_{j}^{*}(2) \frac{e^{2}}{r_{12}} \psi_{i}(1) \psi_{j}(2) d^{3} r=E^{(0)}+C_{i j}
$$

onde $C_{i j}$ é o valor médio entre os estados $i$ e $j$ da interação de Coulomb entre os dois elétrons.

No cálculo acima só consideramos a parte espacial da função de onda e não levamos em conta o princípio de exclusão de Pauli, que requer que a função de onda total seja anti-simétrica nas variáveis espaciais e de spin. Quanto à parte de spin, a álgebra de momentos angulares para dois spins $1 / 2$ nos fornece quatro estados caracterizados pelo seu spin total $S$ :

$$
S=0 \quad \Rightarrow \quad \text { Singleto } \quad\left|\Phi_{0}\right\rangle=\frac{1}{\sqrt{2}}(|\uparrow \downarrow\rangle-|\downarrow \uparrow\rangle)
$$


e

$$
S=\hbar \Rightarrow \text { Tripleto } \quad\left|\Phi_{1}\right\rangle=\left\{\begin{array}{c}
|\uparrow \uparrow\rangle \\
|\downarrow \downarrow\rangle \\
\frac{1}{\sqrt{2}}(|\uparrow \downarrow\rangle+|\downarrow \uparrow\rangle)
\end{array}\right.
$$

Como o Hamiltoniano não depende das coordenadas de spin, $\left[\hat{H}, \hat{S}^{2}\right]=0$ e $\left[\hat{H}, \hat{S}_{z}\right]=0$, podemos escrever a função de onda total como o produto direto entre as funções de onda da parte espacial e da parte de spin, isto é,

$$
\Psi_{s}=\frac{1}{\sqrt{2}}\left[\psi_{i}(1) \psi_{j}(2)+\psi_{i}(2) \psi_{j}(1)\right] \Phi_{0}
$$

$\mathrm{Ou}$

$$
\Psi_{t}=\frac{1}{\sqrt{2}}\left[\psi_{i}(1) \psi_{j}(2)-\psi_{i}(2) \psi_{j}(1)\right] \Phi_{1}
$$

sendo que $\Phi_{0}$ é anti-simétrica e $\Phi_{1}$ é simétrica pela troca do spin (1) pelo spin (2).

Desconsiderando o termo $\hat{U}_{\text {int }}$ as Eqs. (2.8) e (2.9) resultam em um mesmo valor de energia. Levando então em conta a interação obtemos por teoria de perturbação de primeira ordem

$$
\begin{aligned}
& E_{s}=E^{(0)}+C_{i j}+J_{i j} \\
& E_{t}=E^{(0)}+C_{i j}-J_{i j},
\end{aligned}
$$

onde

$$
J_{i j}=\int \psi_{i}^{*}(1) \psi_{j}^{*}(2) \frac{e^{2}}{r_{12}} \psi_{i}(2) \psi_{j}(1) d^{3} r
$$

é denominada energia de troca de dois elétrons nos estados $i$ e $j$. Dessa maneira, o singleto (spins antiparalelos) e o tripleto (spins paralelos) possuem energias diferentes e o estado 
fundamental depende do sinal do termo $J_{i j} ; J_{i j}>0$ indica ordenamento ferromagnético e $J_{i j}<0$ ordenamento antiferromagnético.

Podemos descrever a energia dos quatro estados (singleto e tripleto) pelo Hamiltoniano

$$
\hat{H}=E_{s}+c\left(\hat{\vec{S}}_{1}+\hat{\vec{S}}_{2}\right)^{2}
$$

onde $c$ é uma constante proporcional a $\left(E_{t}-E_{s}\right)$, ou seja, proporcional a $J_{i j}$ (na verdade $\left.c=\frac{\left(E_{t}-E_{s}\right)}{2}\right)$, escolhida para que quando o spin total $S$ for igual a $\hbar$, o Hamiltoniano assuma o valor $E_{t}$. Expandindo o quadrado no lado direito da Eq. (2.13) temos

$$
\hat{H}=E_{s}+c \hat{\vec{S}}_{1}^{2}+c \hat{\vec{S}}_{2}^{2}+2 c \hat{\vec{S}}_{1} \cdot \hat{\vec{S}}_{2}
$$

Os três primeiros termos do lado direito da Eq. (2.14) são constantes, absorvidas em uma redefinição do zero de energia. O Hamiltoniano resultante é então dado por

$$
\hat{H}=2 c \hat{\vec{S}}_{1} \cdot \hat{\vec{S}}_{2}=-J \hat{\vec{S}}_{1} \cdot \hat{\vec{S}}_{2}
$$

com $J=J_{12}$ no caso de dois elétrons. O Hamiltoniano (2.15) fornece os mesmos autovalores que o inicial (2.2), na situação de elétrons localizados.

Em 1928, Dirac (15) mostrou para o caso especial de elétrons localizados, que o princípio de Pauli poderia então ser levado em conta adicionando-se ao Hamiltoniano um termo da forma

$$
\sum_{i<j} \hat{\mathbf{S}}_{\mathbf{i}} \cdot \hat{\mathbf{S}}_{\mathbf{j}}
$$

com $\hat{\mathbf{S}}_{i}$ um operador de spin atuando no i-ésimo sítio de uma rede.

Este resultado sugere que a dependência da energia com o spin, advinda do princípio de Pauli, pode ser contabilizada por uma interação spin-spin da forma

$$
\hat{H}=\sum_{<i, j>} J_{i j} \hat{\mathbf{S}}_{\mathbf{i}} \cdot \hat{\mathbf{S}}_{\mathbf{j}}
$$

com $J_{i j}$ sendo o termo de troca entre os spins dos sítios $i$ e $j$. O Hamiltoniano (2.17) 
é conhecido como Hamiltoniano de Heisenberg e é aplicado na descrição de sistemas em que os momentos magnéticos interagentes estão bem localizados.

A aplicação usual do modelo é feita a sistemas homogêneos em que $J_{i j}=J$, se $i$ e $j$ forem sítios primeiros vizinhos, e $J_{i j}=0$ caso contrário. Apesar dessa simplificação em termos de sistemas reais, o modelo possui solução analítica somente para uma cadeia linear de spins $S=1 / 2$ por meio do Ansatz de Bethe (5). Para spins maiores, dimensionalidade mais alta ou situações inomogêneas, resultados precisos são conhecidos apenas numericamente.

A aproximação mais simples para o Hamiltoniano (2.17) é a de campo médio, que substitui os operadores $\hat{\mathbf{S}}_{i}$ por spins clássicos $\vec{S}_{i}$. Nessa aproximação a energia do estado fundamental de um sistema de tamanho $L$, com valor $S$ para o spin, dimensionalidade $d$ e condição de contorno periódica, é dada por

$$
E_{0}^{C M}=-L J d S^{2}
$$

A expressão acima leva ao resultado correto quando a interação é ferromagnética; já para o caso antiferromagnético, a solução (2.18) não é uma boa estimativa para a energia, pois despreza as flutuações quânticas.

Para o caso antiferromagnético, uma estimativa melhor para $E_{0}$ é dada pela teoria de Ondas de Spin (Spin-wave) (7)

$$
E_{0}^{S W}=-L J d S^{2}+L J d^{-1 / 5}\left(\frac{2}{\pi}-1\right) S
$$

Recentemente, utilizando a técnica numérica do Grupo de Renormalização da Matriz Densidade (DMRG), propôs-se na Ref. (8) a seguinte expressão para a energia de uma cadeia unidimensional de spins $S$

$$
\begin{aligned}
E_{0}^{D M R G}= & -L J S^{2}+L J\left[\left(\frac{2}{\pi}-1\right) S-0.03262-\frac{0.0030}{S}+\frac{0.0015}{S^{3}}-\right. \\
& \left.L J\left(0.338-\frac{0.28}{S}+\frac{0.035}{S^{3}}\right) e^{-\pi S} \cos (2 \pi S)\right]
\end{aligned}
$$


onde os termos cúbicos em $1 / S$ foram acrescentados na Ref. (9).

As expressões resultantes para $E_{0}$ possuem uma grande limitação, só são aplicáveis a sistemas homogêneos, nos quais todos os sítios da rede são equivalentes. Entretanto, em sistemas reais inomogeneidades tais como efeitos de tamanho finito, impurezas substitucionais (spins diferentes) e defeitos na rede, são comuns, e introduzem enormes dificuldades na implementação dos métodos de aproximação descritos acima. Uma técnica que proporciona uma ponte entre sistemas homogêneos e não homogêneos é a Teoria do Funcional da Densidade (DFT), que exploraremos neste trabalho. 


\section{Capítulo 3}

\section{Teoria do Funcional da Densidade}

Segundo a Mecânica Quântica, todas as informações que possivelmente poderíamos ter sobre um dado sistema estão contidas em sua função de onda, $\Psi$. Essa função é obtida a partir da equação de Schrödinger, que para uma partícula num potencial $V(\vec{r})$ é dada por

$$
\left[-\frac{\hbar^{2}}{2 m} \nabla^{2}+V(\vec{r})\right] \Psi(\vec{r})=\epsilon \Psi(\vec{r})
$$

Se houver mais de uma partícula no sistema a equação de Schrödinger torna-se

$$
\left[\sum_{i}^{N}\left(-\frac{\hbar^{2}}{2 m_{i}} \nabla_{i}^{2}+V\left(\vec{r}_{i}\right)\right)+\sum_{i<j} U\left(\vec{r}_{i}, \vec{r}_{j}\right)\right] \Psi\left(\vec{r}_{1}, \ldots, \vec{r}_{N}\right)=E \Psi\left(\vec{r}_{1}, \ldots, \vec{r}_{N}\right)
$$

onde $N$ é o número de partículas, $V\left(\vec{r}_{i}\right)$ é o potencial que atua sobre a i-ésima partícula e $U\left(\vec{r}_{i}, \vec{r}_{j}\right)$ representa a interação entre as partículas.

É somente através do termo $U\left(\vec{r}_{i}, \vec{r}_{j}\right)$ que o Hamiltoniano de uma partícula (Eq. 3.1), eventualmente mais simples, transforma-se em um problema complexo de muitos corpos, e é nesse contexto que a DFT (Density Functional Theory) é aplicada.

A DFT, utilizada freqüentemente no cálculo de estruturas eletrônicas, baseia-se na distribuição da densidade de partículas $(n(\vec{r}))$ ao invés de estar fundamentada no conceito de função de onda.

Na Ref. (16) mostra-se que a densidade de partículas do estado fundamental determina 
completamente a função de onda desse estado. Essa é uma grande simplifacação, pois pode-se trocar a função de onda que depende de muitas variáveis por uma função escalar de uma única variável, $\vec{r}$. Assim, a função de onda pode ser expressa como

$$
\Psi_{0}=\Psi_{0}\left[n_{0}(\vec{r})\right]\left(\vec{r}_{1}, \ldots, \vec{r}_{N}\right)
$$

que indica que $\Psi_{0}$ é uma função de suas variáveis espaciais mas também um funcional de $n_{0}(\vec{r})$.

A propriedade expressa na Eq. (3.3) constitui a essência do teorema de HohenbergKohn. Para o modelo de Heisenberg Eq. (2.17), o teorema foi demonstrado pela primeira vez na Ref. (9) (a demonstração do teorema se encontra no Apêndice B) e estabelece que a variável fundamental do sistema é $\vec{S}_{i}=\left\langle\Psi_{0}\left|\hat{\mathbf{S}}_{\mathbf{i}}\right| \Psi_{0}\right\rangle$, o valor esperado do operador spin em cada sítio. Mostra-se que para um sistema com quaisquer interações $J_{i j}$, a função de onda do estado fundamental é um funcional da distribuição de spins, $\Psi=\Psi\left[\vec{S}_{i}\right]$.

Como conseqüência tem-se que o valor esperado de qualquer observável $\hat{O}$ no estado fundamental é um funcional de $\vec{S}_{i}$

$$
O_{0}\left[\vec{S}_{i}\right]=\left\langle\Psi_{0}\left[\vec{S}_{i}\right]|\hat{O}| \Psi_{0}\left[\vec{S}_{i}\right]\right\rangle
$$

e em particular a própria energia

$$
E_{0}=E_{0}\left[\vec{S}_{i}\right]=\left\langle\Psi_{0}\left[\vec{S}_{i}\right]|\hat{H}| \Psi_{0}\left[\vec{S}_{i}\right]\right\rangle
$$

permitindo que a DFT seja aplicada também a sistemas inomogêneos.

Em geral, faz-se necessária uma aproximação para a energia total do sistema como um funcional da distribuição dos spins, que será diretamente minimizada em relação à variável $\vec{S}_{i}$.

A energia fornecida pela aproximação de campo médio é naturalmente um funcional dos spins

$$
E_{0}^{C M}\left[\vec{S}_{i}\right]=\sum_{<i, j>} J_{i j} \vec{S}_{i} \cdot \vec{S}_{j}
$$


Sabemos porém, que a expressão (3.6) despreza a parte quântica do sistema e melhores aproximações são necessárias, isto é, a construção de melhores funcionais.

Assim, em analogia à DFT aplicada a cálculos de estrutura eletrônica, em que a energia total de um sistema inomogêneo arbitrário é escrita como (9)

$$
E_{0}[n(\mathbf{r})]=T_{s}[n(\mathbf{r})]+E_{H}[n(\mathbf{r})]+E_{v}[n(\mathbf{r})]+E_{x c}[n(\mathbf{r})]
$$

onde $T_{s}$ é a energia cinética do sistema não-interagente, $E_{H}$ é a energia de Hartree, $E_{v}$ a energia potencial proveniente do potencial externo $v(\mathbf{r})$ e $E_{x c}$ é a energia de troca e correlação, escrevemos a energia total de um sistema com qualquer distribuição de spins como

$$
E_{0}\left[\vec{S}_{i}\right]=E_{0}^{C M}\left[\vec{S}_{i}\right]+E_{0}^{C}\left[\vec{S}_{i}\right]
$$

onde o termo $E_{0}^{C}\left[\vec{S}_{i}\right]$ é denominado energia de correlação e inclui tudo o que foi perdido pela aproximação de campo médio. No Hamiltoniano de Heisenberg não há parte cinética e o termo "energia de troca e correlação" é substituído por "energia de correlação", já que o Hamiltoniano é inteiramente devido à interação de troca.

O intuito agora é procurar pela melhor aproximação para $E_{0}^{C}$, pois encontrar a expressão exata para a mesma pode ser tão difícil quanto determinar $E_{0}$.

A aproximação mais simples, aplicada ao modelo de Heisenberg, é a LSA (Local Spin Approximation), que consiste em substituir localmente a energia de correlação do sistema inomogêneo por aquela do sistema homogêneo de mesma distribuição de spins:

$$
E^{C}\left[\mathbf{S}_{i}\right] \approx E_{L S A}^{C}\left[\mathbf{S}_{i}\right]=\left.\sum_{i=1}^{L} \frac{E_{h o m}^{C}(S)}{L}\right|_{S \rightarrow\left|\mathbf{S}_{i}\right|}
$$

Na Ref. (10) são mostrados os resultados da aplicação da LSA a sistemas contendo impurezas substitucionais e utiliza as expressões fornecidas pela SW e DMRG ((2.19) e (2.20) respectivamente) para obter a energia de correlação, ou seja,

$$
E_{C}^{L S A-S W}=J d^{-1 / 5}\left(\frac{2}{\pi}-1\right) \sum_{i}\left|\vec{S}_{i}\right|
$$




$$
\begin{aligned}
E_{C}^{L S A-D M R G=} & J \sum_{i}\left[\left(\frac{2}{\pi}-1\right)\left|\vec{S}_{i}\right|-0.03262-\frac{0.0030}{\left|\vec{S}_{i}\right|}+\frac{0.0015}{\left|\vec{S}_{i}\right|^{3}}-\right. \\
& \left.\left(0.338-\frac{0.28}{\left|\vec{S}_{i}\right|}+\frac{0.035}{\left|\vec{S}_{i}\right|^{3}}\right) e^{-\pi\left|\vec{S}_{i}\right|} \cos \left(2 \pi\left|\vec{S}_{i}\right|\right)\right]
\end{aligned}
$$

As relações (3.10) e (3.11) aplicam-se somente a sistemas com inomogeneidades causadas por spins diferentes na rede. Estamos interessados, entretanto, no caso em que tais inomogeneidades advêm da presença de defeitos nas ligações (Fig. 3.1), isto é, a distribuição de $J_{i j}$ é não-uniforme.

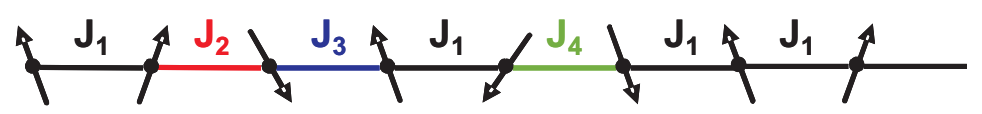

Figura 3.1: Cadeia com defeitos nas ligações.

Desse modo, propôs-se em analogia à LSA, uma aproximação local para as ligações (Local Bond Approximation - LBA), de forma que a energia de correlação do sistema não-homogêneo é construída de acordo com a expressão

$$
E^{C}\left[J_{i}, \vec{S}_{i}\right] \approx E_{L B A}^{C}\left[J_{i}, \vec{S}_{i}\right]=\left.\sum_{i=1}^{L} \frac{E_{h o m}^{C}(J, S)}{L}\right|_{J \rightarrow J_{i}}
$$

em total analogia com a Eq. (3.9). A LBA é uma idéia nova e foi considerada primeiramente na Ref. (17). Aqui, no entanto, apresentamos uma nova maneira de implementá-la, o que traz resultados mais precisos quando comparados aos dados numericamente exatos obtidos por diagonalização de pequenas cadeias. Isso ocorre porque nossa implementação é não-local nas ligações $J_{i}$, ao contrário daquela utilizada na Ref. (17). 


\section{Capítulo 4}

\section{Cadeia Alternada}

\section{Antiferromagnética}

A construção de nosso funcional se baseia em um resultado de Barnes e colaboradores (11) para uma cadeia antiferromagnética alternada, em que as ligações se alternam de sítio para sítio. Neste Capítulo vamos apresentar alguns resultados para esse tipo de sistema.

A cadeia alternada de Heisenberg é um sistema quântico de spins que pode ser aplicado para modelar o comportamento magnético de diversos materiais, dentre os quais podemos citar o $(\mathrm{VO})_{2} \mathrm{P}_{2} \mathrm{O}_{7}$ e o $\mathrm{Cu}\left(\mathrm{NO}_{3}\right)_{2} \cdot 2.5 \mathrm{H}_{2} \mathrm{O}$ (18). É uma generalização da cadeia uniforme, dispondo a interação spin-spin alternadamente entre dois valores $J_{1}$ e $J_{2}$. Ocorre quando um material possui dois tipos de ligações importantes, mas não-equivalentes, resultando em uma seqüência de interações $J_{1}-J_{2}-J_{1}-J_{2} \cdots$.

Cadeias alternadas podem também surgir como conseqüência da chamada transição spin-Peierls que acontece quando um sistema antiferromagnético linear, isotrópico e uniforme sofre uma dimerização espacial da posição dos íons, dando origem a interações alternadas de diferentes intensidades. Esse efeito provoca um decréscimo na energia magnética do estado fundamental e um correspondente aumento na energia da rede (contribuição dos fônons). Há um acoplamento entre spins e fônons e quando o equílibrio entre as duas contribuições é estabelecido, ocorre a formação de dímeros minimizando a energia 
do estado fundamental. O interesse em se estudar cadeias alternadas é motivado pela observação experimental do efeito spin-Peierls em materiais como $\mathrm{CuGeO}_{3}$ (19).

\subsection{O Modelo}

A cadeia alternada é representada pelo Hamiltoniano

$$
\hat{H}\left(J_{1}, J_{2}\right)=\sum_{i=1}^{L / 2} J_{1} \hat{\mathbf{S}}_{2 i-1} \cdot \hat{\mathbf{S}}_{2 i}+J_{2} \hat{\mathbf{S}}_{2 i} \cdot \hat{\mathbf{S}}_{2 i+1},
$$

com $L$ igual ao tamanho do sistema e $J_{i}$ representando a interação entre pares de spins vizinhos.

Vamos considerar uma cadeia antiferromagnética $\left(J_{1}, J_{2}>0\right)$ de spins $S=1 / 2 \mathrm{e}$ condições de contorno periódicas, isto é, $\mathbf{S}_{L+1} \equiv \mathbf{S}_{1}$.

Podemos reescrever a Eq. (4.1) em termos de $J_{1} \equiv J$ e de um parâmetro $\alpha, J_{2} \equiv \alpha J$, que indica como as ligações se alternam, tal que o Hamiltoniano seja então dado por

$$
\hat{H}(J, \alpha J)=\sum_{i=1}^{N_{d}} J \hat{\mathbf{S}}_{2 i-1} \cdot \hat{\mathbf{S}}_{2 i}+\alpha J \hat{\mathbf{S}}_{2 i} \cdot \hat{\mathbf{S}}_{2 i+1},
$$

onde $N_{d}=\frac{L}{2}$ é o número de dímeros independentes ou células unitárias formados por uma ligação $J$ e outra $\alpha J$, conforme ilustra a Fig. 4.1.

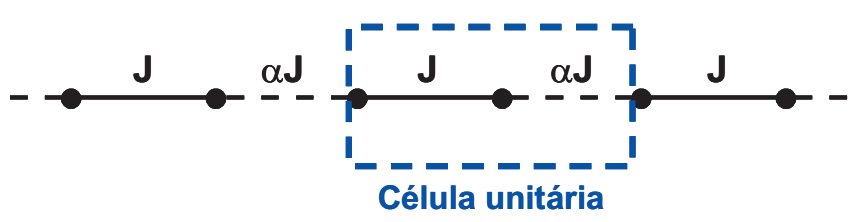

Figura 4.1: Cadeia unidimensional alternada.

Alguns resultados analíticos são conhecidos para a cadeia alternada. Para $\alpha=1$ esse sistema é uma cadeia de spins $(S=1 / 2)$ uniforme e isotrópica cujo valor da energia do estado fundamental, no limite termodinâmico, é conhecido através do Ansatz de Bethe (5),

$$
\alpha=1 \quad \Rightarrow \quad e_{0} \equiv \frac{E_{0}}{L J}=\frac{1}{4}-\ln 2=-0.443147 \ldots
$$


Para $\alpha=0$ o sistema se reduz a dímeros desacoplados. O Hamiltoniano é simplesmente o de duas partículas interagindo através de uma ligação $J$, sendo a energia do estado fundamental dada por

$$
\alpha=0 \Rightarrow \hat{H}=\frac{J}{2}{\hat{S_{T}}}^{2}-\frac{J}{2} \sum_{i=1}^{2}{\hat{S_{i}}}^{2} \Rightarrow e_{0}^{\text {dímero }}=-\frac{1}{2} s(s+1)=-\frac{3}{8}
$$

e o autovetor correspondente é o singleto,

$$
|S=0\rangle=\frac{1}{\sqrt{2}}(|\uparrow \downarrow\rangle-|\downarrow \uparrow\rangle)
$$

Neste caso, o estado fundamental do Hamiltoniano total é o produto direto entre os estados fundamentais dos dímeros

$$
\left|\Psi_{0}\right\rangle=\prod_{n=1}^{N_{d}}\left|\varphi_{n}^{0}\right\rangle
$$

com energia

$$
E_{0}=N_{d} E_{0}^{\text {dímero }}=-L J \frac{3}{8}
$$

Podemos também obter algumas relações entre as energias e suas derivadas partindo da identidade obedecida pelo Hamiltoniano (4.2). Notemos a relação de proporcionalidade

$$
\hat{H}(J, \alpha J)=\alpha \hat{H}\left(\alpha^{-1} J, J\right)
$$

Considerando a equação de autovalores para os Hamiltonianos da Eq. (4.8),

$$
\hat{H}(J, \alpha J)\left|\Psi_{n}\right\rangle=E_{n}(J, \alpha J)\left|\Psi_{n}\right\rangle \quad \text { e } \quad \hat{H}\left(\alpha^{-1} J, J\right)\left|\Psi_{n}\right\rangle=E_{n}\left(\alpha^{-1} J, J\right)\left|\Psi_{n}\right\rangle
$$

e a Eq. (4.2), as energias satisfazem a relação

$$
\frac{E_{n}(\alpha)}{J}=\alpha \frac{E_{n}\left(\alpha^{-1}\right)}{J},
$$

para qualquer estado $n$. 
Para o estado fundamental em particular $(n=0)$, vamos diferenciar (4.10) em relação a $\alpha$ assumindo, no entanto, que não existam singularidades. Temos então

$$
\begin{gathered}
\left.\frac{d e_{0}}{d \alpha}\right|_{\alpha \rightarrow 0}=0 \\
\left.\frac{d e_{0}}{d \alpha}\right|_{\alpha=1}=\frac{e_{0}(1)}{2}=\frac{1}{8}-\frac{\ln 2}{2} .
\end{gathered}
$$

\subsection{Motivação}

A construção de um funcional da energia que seja capaz de reproduzir situações em que defeitos nas ligações estejam presentes foi motivada pelo estudo da cadeia alternada antiferromagnética, já que nesta descrição, as interações não possuem a mesma intensidade, diferentemente do caso usual de aplicação do modelo de Heisenberg.

O desenvolvimento da pesquisa teve como base os resultados, particularmente para o estado fundamental, da Ref. (11), sendo o mais importante de todos eles a expressão da energia do estado fundamental em termos do parâmetro $\alpha$.

Dessa maneira, para o caso de $\alpha$ qualquer propõe-se na Ref. (11) o resultado

$$
e_{0}(\alpha) \equiv-\frac{3}{2^{3}}+f(\alpha)
$$

onde $f(\alpha)$ é dada por

$$
\begin{aligned}
f(\alpha)= & -\frac{3}{2^{6}} \alpha^{2}-\frac{3}{2^{8}} \alpha^{3}-\frac{13}{2^{12}} \alpha^{4}-\frac{89}{2^{14} \times 3} \alpha^{5}-\frac{463}{2^{17} \times 3} \alpha^{6}- \\
& \frac{7 \times 61 \times 191}{2^{22} \times 3^{3}} \alpha^{7}-\frac{11 \times 139 \times 271}{2^{21} \times 3^{4} \times 5} \alpha^{8}-\frac{107 \times 22005559}{2^{30} \times 3^{5} \times 5^{2}} \alpha^{9} .
\end{aligned}
$$

Essa série para $e_{0}(\alpha)$ foi obtida através de cálculo perturbativo baseado em resultados numéricos (extrapolação para o limite de "bulk") e válida para $\alpha$ no intervalo $[0,1]$.

Nos gráficos a seguir (Figs. 4.2 e 4.3) fazemos uma comparação entre os dados obtidos com a Eq. (4.13) e os nossos resultados numéricos obtidos de um programa em linguagem 
Fortran 90 que escrevemos, baseado no método de potências sucessivas de $H$ (ver Apêndice A). Para tal comparação escolhemos duas situações específicas: $L$ par com condição de contorno periódica (ccp) e L ímpar com condição de contorno aberta (cca).

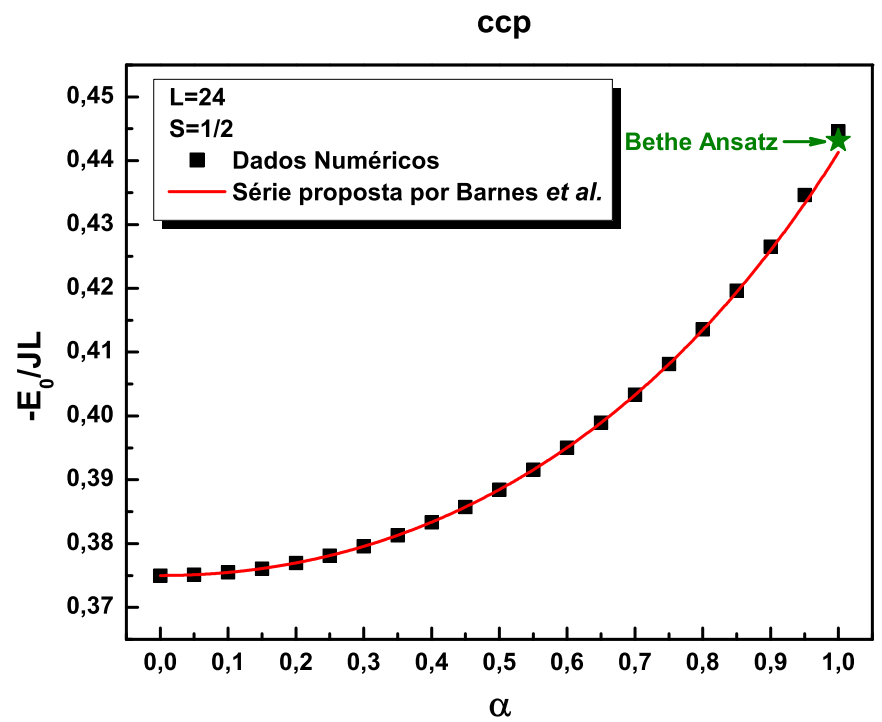

Figura 4.2: Comparação entre a energia do estado fundamental, por ligação, de uma cadeia de 24 spins $1 / 2$ (condição de contorno periódica) com a série proposta na Ref. (11).

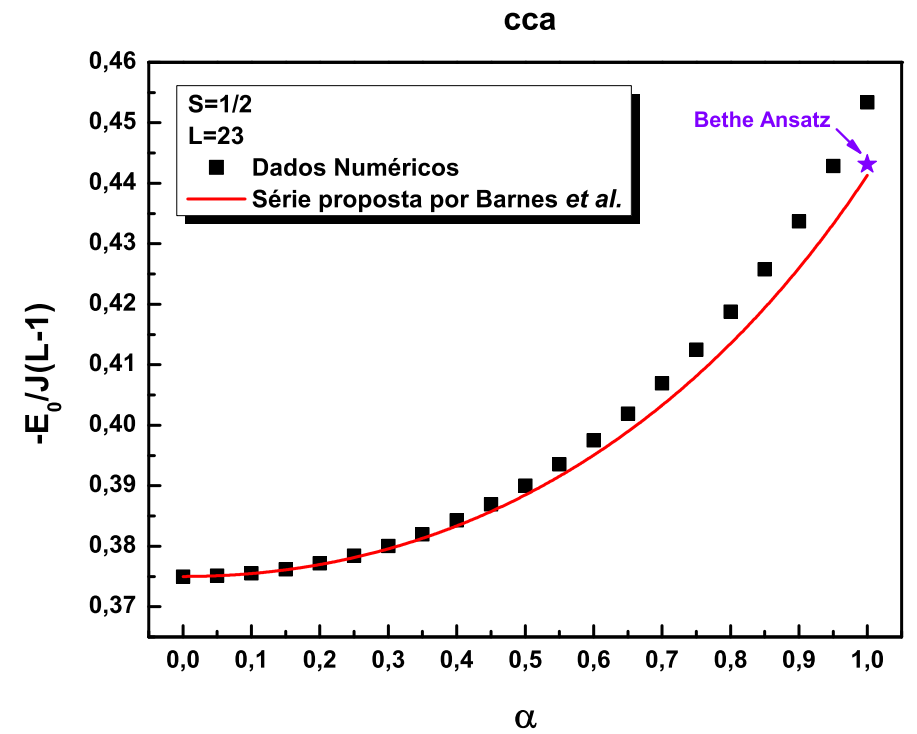

Figura 4.3: Comparação entre a energia do estado fundamental, por ligação, de uma cadeia de 23 spins $1 / 2$ (condição de contorno aberta) com a série proposta na Ref. (11).

Para $L=24$ e condição de contorno periódica observamos uma boa concordância entre os resultados apesar da rede usada ser relativamente pequena, já que a série (4.13) é uma extrapolação para $L \rightarrow \infty$. Notamos também que a concordância entre os dados é melhor 
para $\alpha<1$, o que era de se esperar, pois a expansão é válida para $\alpha$ pequeno. Apesar disso, vemos na Fig. 4.2 que ela ainda é boa para $\alpha$ na região próxima de 1.

Para $L=23$ e condição de contorno aberta, os dados também se ajustam à série proposta, cometendo um erro maior $(\approx 3 \%)$ à medida que $\alpha \rightarrow 1$. Essa pequena discordância, maior para cca do que para ccp, se deve ao tamanho finito do sistema (bordas).

Observemos também que, para $\alpha=1$ nosso resultado é ligeiramente diferente daquele dado pelo Bethe Ansatz; isso porque esse último fornece a energia do estado fundamental no limite termodinâmico.

Notemos que, nosso interesse estando voltado para as interações entre as partículas, não adotamos, como é comum, expressar a energia $E_{0}$ em termos do número de partículas do sistema, mas sim pelo número de ligações. Observemos também que para $\alpha=0$, condição de contorno aberta e L ímpar, um spin é desligado da cadeia, fazendo então mais sentido escrever $E_{0}$ em termos do número de ligações. Para ccp o número de partículas é o mesmo que o de ligações. 


\section{Capítulo 5}

\section{Construção do Funcional}

Até o momento, os funcionais obtidos para o modelo de Heisenberg se baseiam em resultados da teoria de Spin-wave ou DMRG. Todos são para cadeias de spins com interações uniformes, a única exceção é a Ref. (17) que explora a possibilidade de construção de um funcional para cadeias em que as ligações sejam não-uniformes. Nesta dissertação propomos um novo funcional (proposição diferente daquela da Ref. (17)) da distribuição de spins que seja aplicável a sistemas com qualquer distribuição das ligações $J_{i j}$ (apenas para primeiros vizinhos). No entanto, ele se restringe a cadeias de spins $1 / 2$. A construção desse funcional, que também é um funcional das ligações, requer que percorramos duas etapas. A primeira delas é o cálculo da energia de campo médio, e em seguida a obtenção da energia de correlação.

\subsection{Campo Médio}

Como mencionado previamente, o campo médio é uma técnica simples de aproximação para o modelo de Heisenberg. Consiste em substituir a variável quântica $\hat{\mathbf{S}}_{\mathbf{i}}$ pela variável clássica $\vec{S}_{i}$. Assim, o Hamiltoniano quântico (2.17) torna-se

$$
E^{C M}=\sum_{i} J_{i} \vec{S}_{i} \cdot \vec{S}_{i+1}
$$

O estado fundamental de uma cadeia uniforme de spins $S$ e interação entre primeiros 
vizinhos $J$ é determinado simplesmente pela configuração que minimiza a energia acima, que no caso antiferromagnético, é a disposição antiparalela dos spins clássicos (estado de Néel) ilustrada na Fig. 5.1.

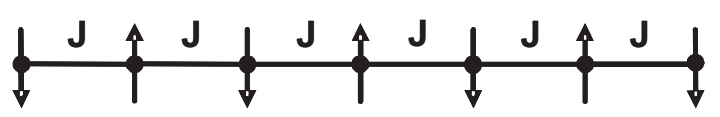

Figura 5.1: Configuração do estado fundamental de uma cadeia com $J>0$ (antiferromagnetismo) segundo campo médio.

Estamos interessados entretanto, em estudar a cadeia alternada (Fig. 5.2), com $J_{1}=J$ e $J_{2}=\alpha J, \alpha=\frac{J_{2}}{J_{1}}>0$.

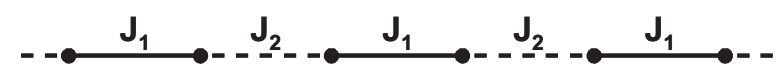

Figura 5.2: Cadeia alternada antiferromagnética, $J_{1}>0$ e $J_{2}>0$.

Desse modo, a energia de uma cadeia com condição de contorno periódica (ccp) e número de sítios $(L)$ par é dada por

$$
\operatorname{ccp}(\mathrm{L} \text { par }) \quad \Rightarrow \quad E_{0}^{C M}(\alpha, S)=-L J S^{2} \frac{(1+\alpha)}{2} .
$$

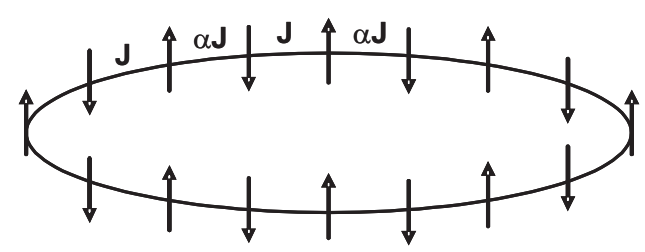

Figura 5.3: Ilustração de uma cadeia alternada com número de sítios par com condição de contorno periódica.

Para o caso de condição de contorno aberta (cca) e número de sítios ímpar temos

$$
\text { cca (L ímpar) } \Rightarrow \quad E_{0}^{C M}(\alpha, S)=-(L-1) J S^{2} \frac{(1+\alpha)}{2} \text {. }
$$

Somente estudamos as duas situações descritas acima, ccp ( $L$ par) e cca ( $L$ ímpar). Embora duas outras possibilidades, ccp ( $L$ ímpar) e cca ( $L$ par), possam ser consideradas, nós não as abordamos, pois o sistema que estamos considerando, cadeia alternada, é 
constituído de células unitárias compostas por uma ligação $J$ e outra $\alpha J$, portanto formado por um número par de ligações. Nessas duas últimas possibilidades o número de ligações é ímpar e uma das células unitárias fica incompleta. Abaixo (Figs 5.4 e 5.5) ilustramos os dois casos em que estamos interessados.

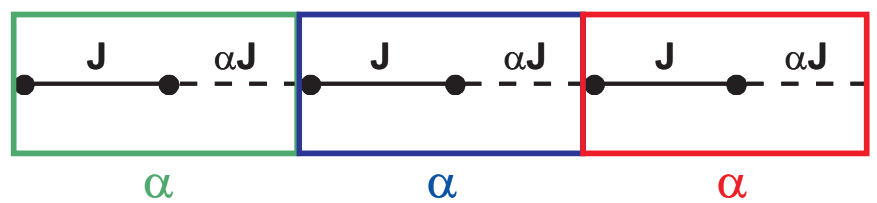

Figura 5.4: Condição de contorno periódica - $L$ par.

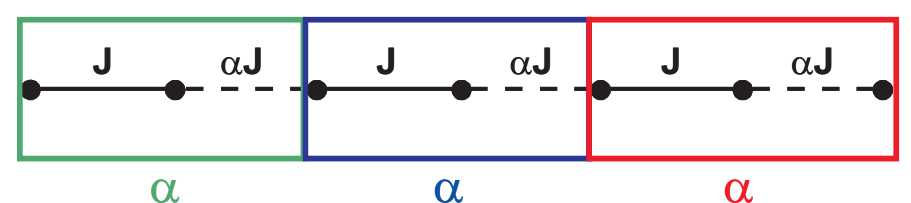

Figura 5.5: Condição de contorno aberta - $L$ ímpar.

Comparamos a seguir os dados obtidos por diagonalização exata e os resultados fornecidos por campo médio para a energia do estado fundamental, por ligação e em unidades de $J \hbar^{2}$, de uma cadeia de spins $S=1 / 2$ em função do parâmetro $\alpha, 0 \leq \alpha \leq 1$.

Podemos observar nas Figs. 5.6 e 5.7 que apesar da facilidade no emprego da técnica de campo médio, os seus resultados apresentam erros médios acima de $50 \%$, e é por essa razão que buscamos utilizar outros métodos de aproximação.

Notemos também que pelo fato de termos considerado a energia por ligação, os resultados de ambos os casos (ccp e cca) tornam-se numericamente próximos (para o campo médio os resultados são idênticos).

Os resultados numericamente exatos foram obtidos a partir de um programa desenvolvido para diagonalizar o Hamiltoniano de cadeias antiferromagnéticas de spins $S=1 / 2$ com quaisquer distribuições de ligações $\left(J_{i j}\right)$. O programa se baseia na conservação do operador $\hat{S}_{z}$ (componente z do spin total) e utiliza, portanto, como base de estados os seus autovetores. A matriz de $\hat{H}$ é construída somente no subespaço de menor componente de $\hat{S}_{z}$, que é onde se encontra o estado fundamental (20). Os sistemas aqui estudados não 


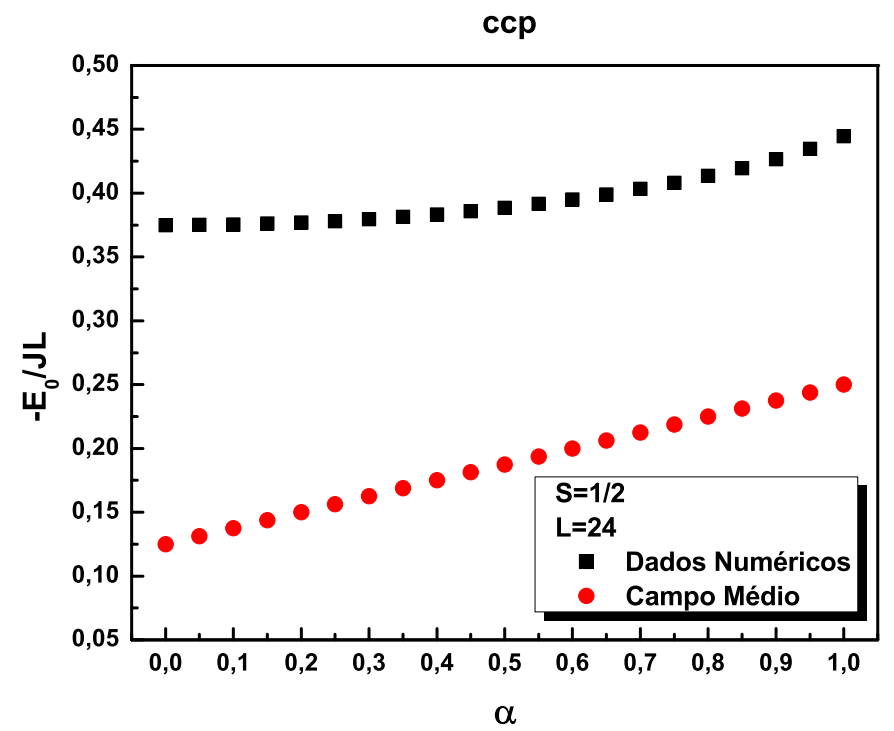

Figura 5.6: Energia do estado fundamental de uma cadeia com $L=24$ sítios e ccp em função do parâmetro $\alpha$. Os dados numéricos são representados pelos quadrados em preto e o campo médio pelos círculos vermelhos.

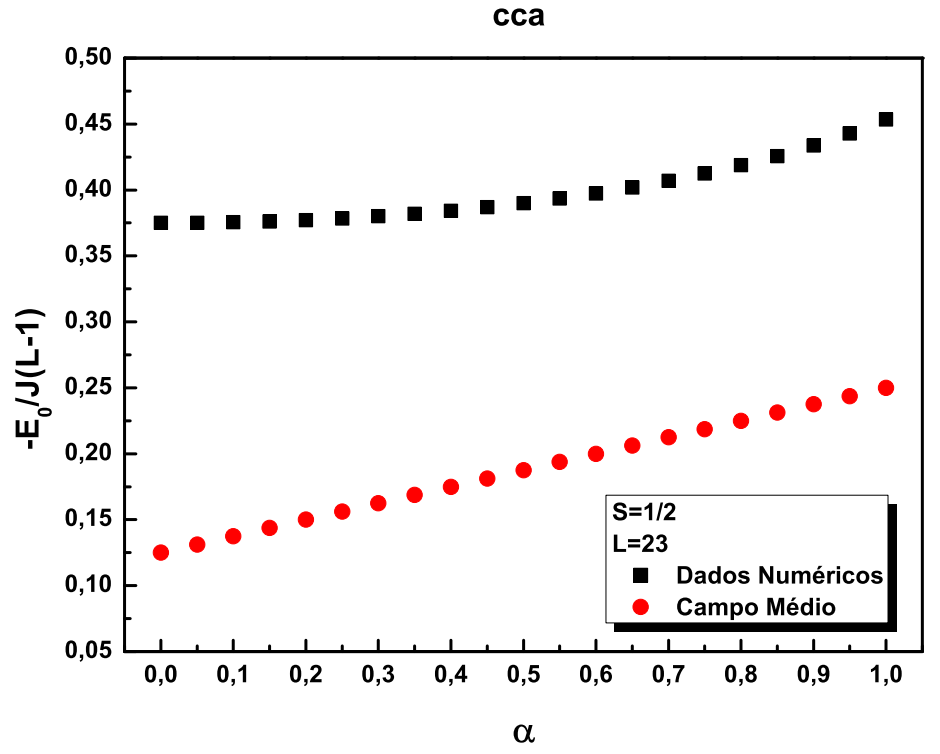

Figura 5.7: Energia do estado fundamental de uma cadeia com $L=23$ sítios e cca em função do parâmetro $\alpha$. Os dados numéricos são representados pelos quadrados pretos e o campo médio pelos círculos vermelhos.

nos permitem explorar simetrias adicionais, como por exemplo invariância translacional, que seria de extrema importância para a redução da memória computacional, pois quando presente bloco diagonaliza a matriz $\hat{H}$.

Na tabela 5.1 mostramos uma estimativa do tempo de CPU e uso de memória para uma cadeia alternada com $\alpha=0.5$, condição de contorno periódica (ccp) e tamanhos de 
rede distintos.

Tabela 5.1: Estimativa de memória e tempo de CPU para diferentes tamanhos de rede, $\alpha=0.5$ e ccp.

\begin{tabular}{|c|c|c|c|}
\hline \hline $\mathrm{L}$ & $e_{0}$ & Tempo de CPU (min) & Memória (Mb) \\
\hline \hline 20 & -0.388465114974584 & $\sim 0.5$ & 16 \\
\hline 24 & -0.388465623120953 & 10.9 & 266 \\
\hline 26 & -0.388465616597454 & 47.7 & 1082 \\
\hline 28 & -0.388465616594 & 600 & $\sim 4 \times 10^{3}$ \\
\hline 30 & -0.388465614 & 923 & $\sim 4 \times 10^{3}$ \\
\hline 32 & -0.388465614 & 1246 & $\sim 4 \times 10^{3}$ \\
\hline 64 & -0.38846559 & $\sim 3713$ & $\sim 4 \times 10^{3}$ \\
\hline \hline
\end{tabular}

Os dados para redes com $L>26$ foram gerados por um programa iterativo ${ }^{1}$ que explora a conservação do operador $\hat{S}^{2}$ sendo $S$ o spin total. Podemos observar que para $L>26$, à medida que o número de spins aumenta, a precisão no valor da energia diminui. Isso deve-se ao fato de que o programa seleciona um determinado número de estados para construir a base utilizada para a obtenção dos autovalores.

Pelo fato de cada novo spin introduzido no sistema aumentar consideravelmente a dimensão do subespaço, e conseqüentemente o tempo de processamento e o uso de memória, foram realizados somente cálculos para cadeias de tamanho máximo $L=24^{2}$. Além disso, vemos que o valor da energia não varia tão significativamente quando caminhamos para o limite termodinâmico $(L \rightarrow \infty)$, levando em conta a precisão dos dados.

Prosseguindo com a construção do funcional nosso próximo passo é o cálculo da chamada energia de correlação.

\subsection{Correlação}

O erro cometido pelo campo médio é uma conseqüência direta do fato de a correlação entre as partículas ter sido desprezada. Para compensar essa falha, adiciona-se a $E_{0}^{C M}$ um termo $E_{0}^{C}$, denominado energia de correlação e obtido da equação

$$
E_{0}(\alpha) \equiv E_{0}^{C M}(\alpha)+E_{0}^{C}(\alpha)
$$

\footnotetext{
${ }^{1}$ Feito por Fabiano Caetano de Souza, aluno de doutorado do Prof. Valter Líbero.

${ }^{2}$ Utilizamos um desktop com as configurações: Pentium 4, CPU 3.00 GHz, 512 MB de RAM.
} 
Ou seja, $E_{0}^{C}$ é por definição a diferença entre o resultado exato e o de campo médio e, portanto, capaz de recuperar, em princípio, tudo o que foi perdido pela aproximação de campo médio.

A Eq. (5.4) envolve portanto, um termo conhecido que é a energia na aproximação de campo médio $\left(E_{0}^{C M}\right)$ e o valor exato da energia $\left(E_{0}\right)$ do sistema, que obviamente desconhecemos. Assim, determinar a energia de correlação é tão difícil quanto obter a energia exata e por essa razão procuramos pela melhor aproximação para $E_{0}$.

A idéia do presente trabalho é utilizar a série (4.13) proposta na Ref. (11) para $E_{0}$, diferentemente de um trabalho anterior (17) que escolheu trabalhar com as conhecidas expressões para a energia do estado fundamental dadas pela Spin-wave (SW) e pelo Grupo de Renormalização da Matriz Densidade (DMRG).

A energia de correlação será então determinada usando-se a aproximação LBA (3.12). Vamos, entretanto, substituir localmente cada dímero $\alpha \rightarrow \alpha_{i}$, ao invés de cada ligação $J \rightarrow J_{i}$, e desse modo obter um funcional de $\alpha_{i}$,

$$
E^{C}\left[\alpha_{i}\right] \approx E_{L B A}^{C}\left[\alpha_{i}\right]=\left.\sum_{i=1}^{N_{d}} \frac{E_{h o m}^{C}(\alpha)}{N_{d}}\right|_{\alpha \rightarrow \alpha_{i}},
$$

onde $\alpha_{i}=\frac{J_{i+1}}{J_{i}}$.

Deste modo, o sistema homogêneo de referência será uma cadeia alternada de spins $S=1 / 2$, como ilustra a Fig. 5.8. Observe que o sistema é homogêneo apenas quando formado por dímeros.

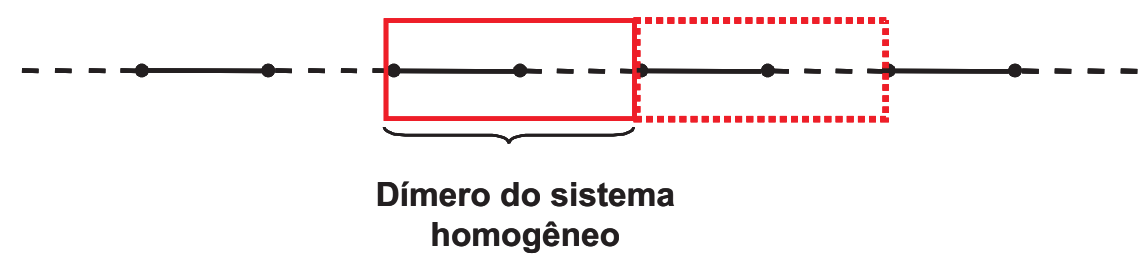

Figura 5.8: Sistema homogêneo, referência para a construção da energia de correlação.

Usando a Eq. (5.2), com $S=1 / 2$, para o campo médio e a Eq. (4.13) para $E_{0}(\alpha)$, a 
energia de correlação do sistema homogêneo é dada por

$$
E_{\text {hom }}^{C}(\alpha)=L J\left(-\frac{1}{4}+\frac{1}{8} \alpha+f(\alpha)\right)
$$

onde $f(\alpha)$ foi definida na Eq. (4.14).

Aplicando a LBA (5.5) obtemos então

$$
E_{L B A}^{C}\left[\alpha_{i}\right]=J \sum_{i=1}^{N_{d}} 2\left(-\frac{1}{4}+\frac{1}{8} \alpha_{i}+f\left(\alpha_{i}\right)\right)
$$

O campo médio é naturalmente um funcional das ligações. Assim, temos que a energia do estado fundamental é $E_{0}^{L B A}\left[\alpha_{i}\right]$ obtida minimizando-se o funcional

$$
E^{L B A}\left[\alpha_{i}, \vec{S}_{i}\right]=J \sum_{i=1}^{L} \alpha_{i} \vec{S}_{i} \cdot \vec{S}_{i+1}+J \sum_{i=1}^{N_{d}} 2\left(-\frac{1}{4}+\frac{1}{8} \alpha_{i}+f\left(\alpha_{i}\right)\right)
$$

nas variáveis de spin. Notemos que somente o termo da energia proveniente da aproximação de campo médio depende do spin. Dessa maneira, apenas esse termo participa na minimização da energia.

A Eq. (5.8) pode ser aplicada a redes com quaisquer distribuições de interações, mas o seu uso limita-se a $0 \leq \alpha_{i} \leq 1$ (tal como a Eq. (4.13)). Lembramos também que nos restringimos aos casos $L$ par (ccp) e $L$ ímpar (cca), pois cada um dos $\alpha_{i}$ se refere a um par de ligações.

Para tratarmos situações em que $\alpha_{i}>1$, exploramos a relação (4.10), isto é, a igualdade,

$$
E_{0}\left(\alpha^{-1}\right)=\alpha^{-1} E_{0}(\alpha)
$$

Utilizando a expressão acima para a determinação da energia de correlação, obtemos uma equação para a energia com $\alpha_{i}>1$, ou seja,

$$
E^{L B A}\left[\alpha_{i}\right]=J \sum_{i=1}^{L} \alpha_{i} \vec{S}_{i} \cdot \vec{S}_{i+1}+J \sum_{i=1}^{N_{d}} 2\left(\frac{1}{8}-\frac{1}{4} \alpha_{i}+\alpha_{i} f\left(\alpha_{i}^{-1}\right)\right) .
$$


Para determinar uma melhor aproximação para a energia nós a separamos em dois termos: energia de campo médio (naturalmente um funcional das ligações) e energia de correlação (que engloba tudo o que a aproximação de campo médio perdeu), fazendo uma aproximação local nesta última. Poderíamos, no entanto, fazer uma aproximação local diretamente na expressão para $e_{0}$ (4.13). A primeira metodologia, entretanto, se mostra mais eficaz e é por essa razão que nós a adotamos.

Nos próximos capítulos vamos mostrar os resultados obtidos com a aplicação dos funcionais a cadeias com defeitos de ligação. 


\section{Capítulo 6}

\section{Defeitos Antiferromagnéticos}

Neste capítulo aplicaremos os funcionais obtidos anteriormente (Eqs. (5.8), (5.10)) a situações com inomogeneidades, sendo que estas se devem tanto a efeitos de borda (dimensão finita do sistema) quanto à presença de defeitos antiferromagnéticos nas ligações. Defeitos do tipo ferromagnéticos serão abordados no Capítulo seguinte.

\subsection{Cadeia alternada com um defeito antiferromagnético}

Primeiramente consideraremos uma cadeia alternada com um defeito $J^{\prime}>0$ no lugar de uma ligação do tipo $\alpha J$, onde $\alpha$ é o parâmetro de alternância (ver Fig. 6.1).

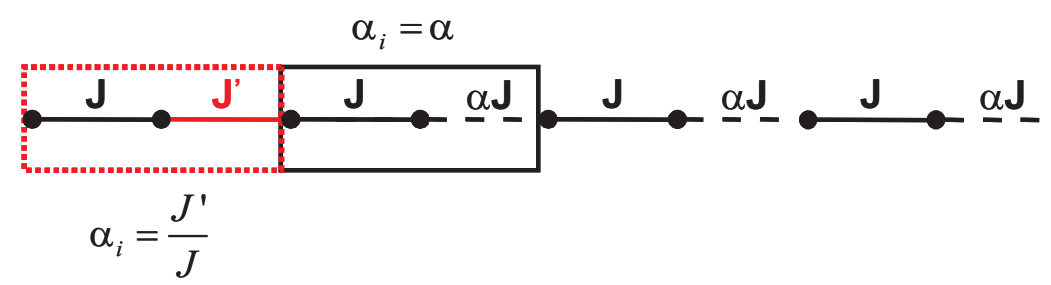

Figura 6.1: Situação 1 - Cadeia alternada com um defeito $J^{\prime}$ no lugar de uma ligação $\alpha J$.

É importante lembrarmos, como pode ser visto na figura acima, que para os funcionais apenas importa a razão $\alpha_{i}=\frac{J_{i+1}}{J_{i}}$, e é esse ponto que distingue as expressões (5.8) $\left(\alpha_{i}<1\right)$ e (5.10) $\left(\alpha_{i}>1\right)$. Assim, o funcional que será utilizado possui uma relação com o defeito 
$\left(J^{\prime}\right)$ inserido, isto é, devemos respeitar as condições

$$
\left\{\begin{array}{c}
\alpha_{i}<1 \rightarrow J^{\prime}<J \\
\alpha_{i}>1 \rightarrow J^{\prime}>J
\end{array}\right.
$$

quando $J^{\prime}$ substituir uma ligação $\alpha J$ (Fig. 6.1), e neste caso o funcional utilizado é aquele dado pela Eq. (5.8).

Há também a possibilidade de ocorrência do defeito em uma ligação do tipo $J$ (Fig. $6.2)$

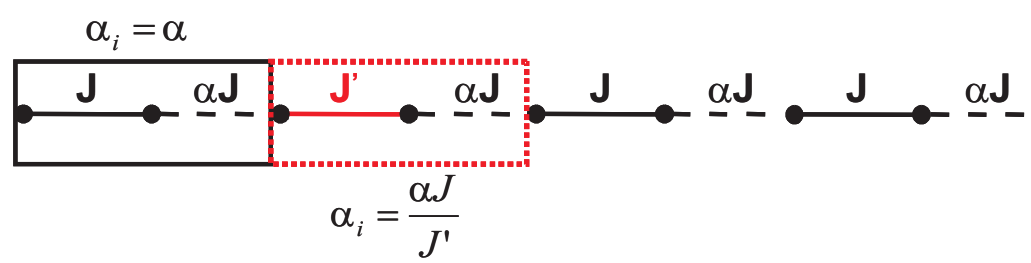

Figura 6.2: Situação 2 - Cadeia alternada com um defeito $J^{\prime}$ no lugar de uma ligação $J$.

e neste caso temos as relações

$$
\left\{\begin{array}{c}
\alpha_{i}<1 \rightarrow J^{\prime}>\alpha J \\
\alpha_{i}>1 \rightarrow J^{\prime}<\alpha J
\end{array}\right.
$$

respeitadas quando usamos o funcional (5.10).

A seguir nas Figs. 6.3 e 6.4 comparamos a energia do estado fundamental (por ligação e em unidades de $J$ ) em função do parâmetro $\alpha$ (ccp e $L=24)$ para dois casos com defeitos de intensidades diferentes (Fig. 6.1), $\frac{J^{\prime}}{J} \approx 0$ e $\frac{J^{\prime}}{J} \approx 1$.

Notamos a boa concordância entre os resultados fornecidos pelo funcional, representados pelos triângulos azuis, e os dados obtidos por diagonalização exata (quadrados pretos), mesmo quando o valor do defeito inserido é próximo a unidade.

Não mostramos aqui os resultados de campo médio, já que o funcional se ajusta muito bem aos dados exatos (o erro não chega a 1\%), e o primeiro, por sua vez, comete erros na energia acima de $50 \%$. 


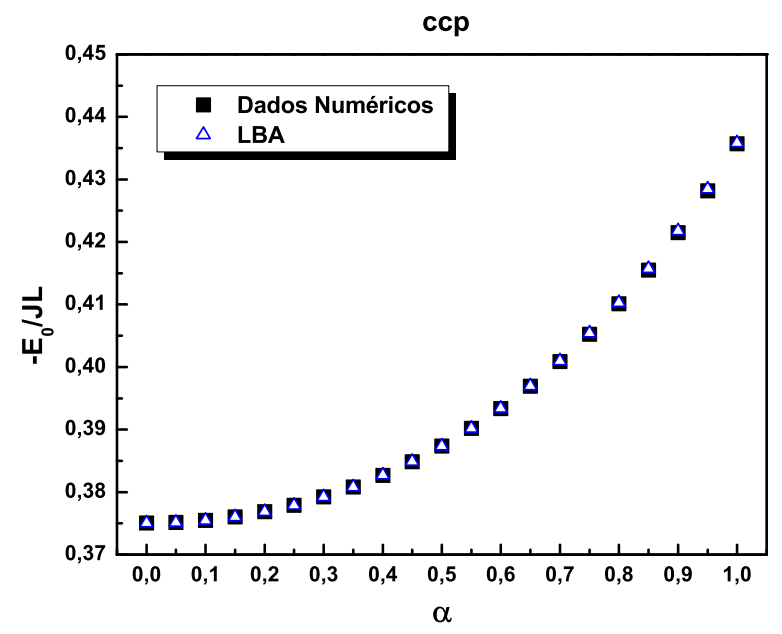

Figura 6.3: Defeito $J^{\prime}=0.10 J$.

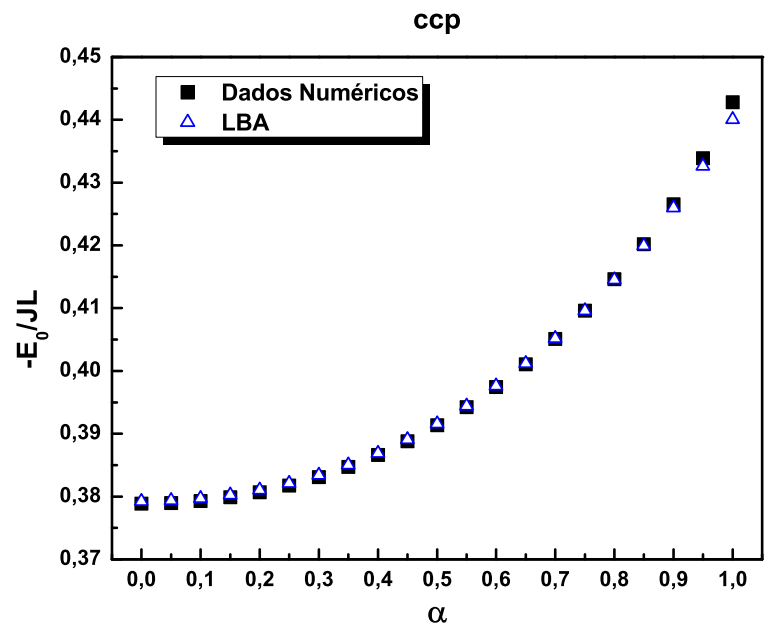

Figura 6.4: Defeito $J^{\prime}=0.90 J$.

\subsection{Cadeia uniforme com um defeito antiferromagnético}

\subsubsection{Condição de Contorno Periódica}

Na seção anterior vimos que um defeito grande $\left(\frac{J^{\prime}}{J} \approx 1\right)$ em uma cadeia alternada não altera o bom ajuste entre os dados numericamente exatos e o funcional. O valor do defeito se torna relevante quando consideramos uma cadeia com todas as ligações iguais, isto é, $J_{i j}=J$, exceto uma delas como ilustrado na Fig. 6.5, e fazemos $J^{\prime} \rightarrow J$. Essa situação pode ser considerada extrema para o funcional, já que nesse limite $\alpha=1$, exceto para uma ligação.

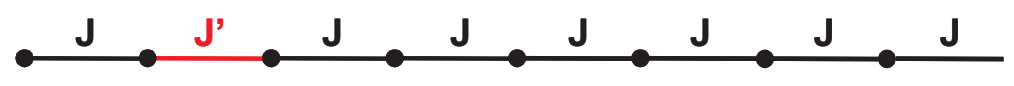

Figura 6.5: Cadeia uniforme com um defeito $J^{\prime}$.

Os gráficos a seguir mostram a comparação entre os resultados exatos, o funcional e campo médio.

Em relação ao campo médio o funcional reproduz muito melhor os resultados numéricos exatos e vemos (Fig. 6.6) no gráfico da direita (observar a escala) a influência do valor do defeito à medida que o sistema se torna uniforme $\left(J^{\prime} \rightarrow J\right)$. O comportamento observado é de certa forma esperado, já que o funcional foi construído tendo como base uma expressão 


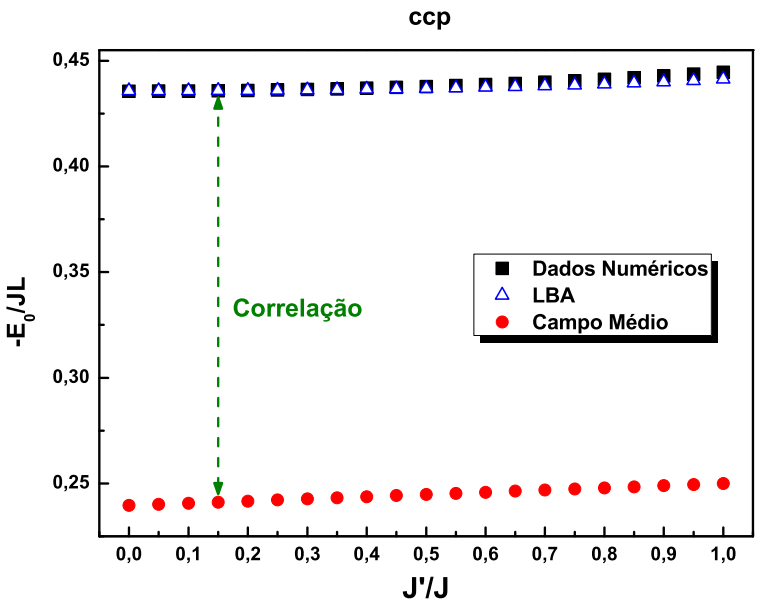

(a)

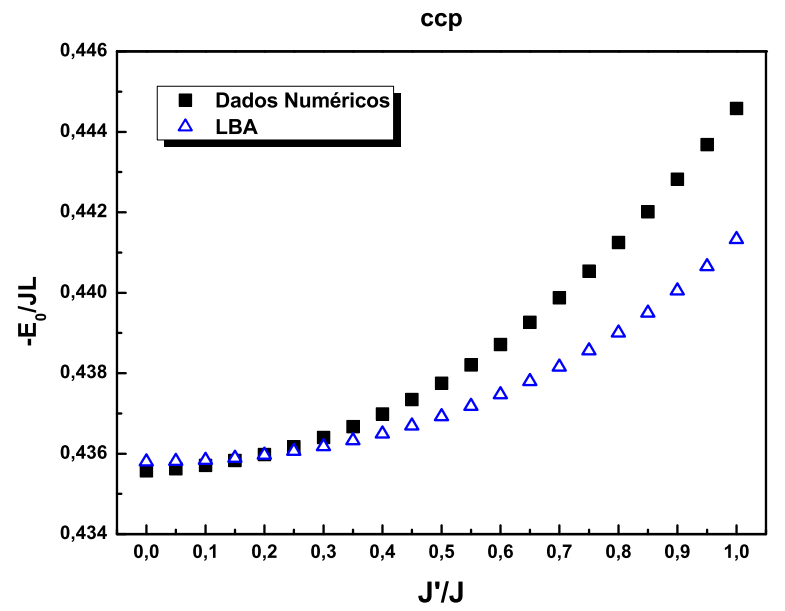

(b)

Figura 6.6: Energia do estado fundamental por ligação e em unidades de $J$ em função do defeito $J^{\prime}$. Os dados numericamente exatos são representados pelos quadrados pretos, LBA pelos triângulos azuis e campo médio pelos círculos vermelhos. Em (b) temos em escala ampliada os resultados exatos e o funcional.

da energia válida para $\alpha \ll 1$. A discordância funcional-valores exatos mesmo para $J^{\prime} \approx J$, no entanto, é pequena; o erro é de aproximadamente $1 \%$.

\subsubsection{Condição de Contorno Aberta}

Vamos tratar aqui situação semelhante à anterior (Fig. 6.5), porém, consideraremos uma cadeia com $L=23$ e condição de contorno aberta. Além disso, mostraremos os resultados do funcional para $\alpha_{i}<1$, Eq. (5.8) e do funcional para $\alpha_{i}>1$, Eq. (5.10).

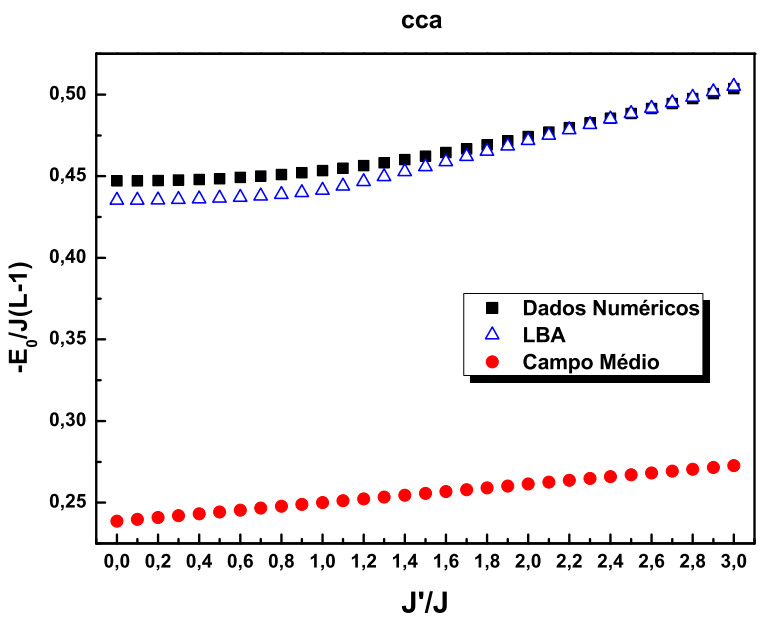

(a)

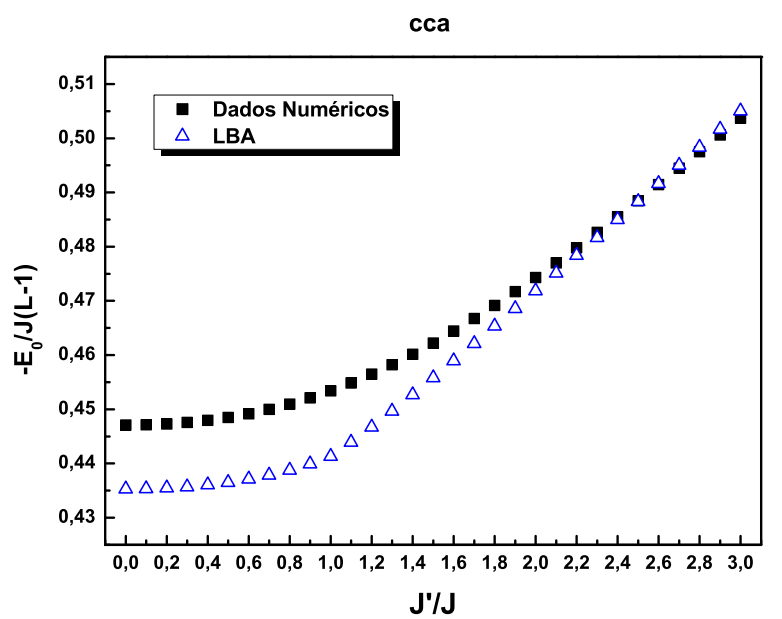

(b)

Figura 6.7: Energia do estado fundamental por ligação e em unidades de $J$ em função do defeito $J^{\prime}$ para condição de contorno aberta. Os dados obtidos por diagonalização exata são representados pelos quadrados pretos, LBA pelos triângulos azuis e campo médio pelos círculos vermelhos. Em (b) temos em escala ampliada os resultados exatos e o funcional. 
Nesse exemplo o funcional não se ajusta tão bem quanto no caso anterior para defeitos pequenos, apesar do erro estimado ser em torno de $3 \%$ apenas. O ajuste se torna melhor quando $J^{\prime}>J$. Lembremos que o funcional utilizado nesse intervalo (Eq. (5.10)) envolve o quociente de $\alpha_{i}$, por isso é mais eficiente à medida que $J^{\prime}$ cresce $\left(\alpha_{i}>1\right)$.

\subsection{Cadeias com vários defeitos}

Voltando nossa atenção para a posição do defeito na cadeia, vamos testar o funcional em um sistema com defeitos presentes tanto em ligações do tipo $\alpha J$ quanto do tipo $J$.

Consideramos então uma cadeia alternada com três ligações substitucionais. As tabelas 6.1 e 6.2 indicam os defeitos e as suas respectivas posições que podem ser observadas nas ilustrações 6.8 e 6.9 .

Tabela 6.1: Caso 1.

\begin{tabular}{|c|c|}
\hline Defeito & Posição \\
\hline \hline$J^{\prime}=0.10 J$ & Ligação $\alpha J$ \\
\hline$J^{\prime \prime}=0.70 J$ & Ligação $\alpha J$ \\
\hline$J^{\prime \prime \prime}=0.90 J$ & Ligação $J$ \\
\hline
\end{tabular}

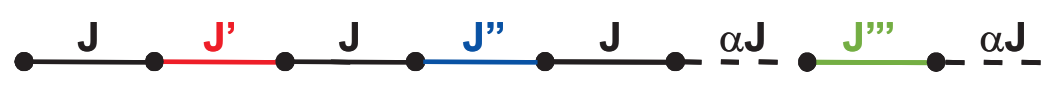

Figura 6.8: Caso 1 - cadeia com três defeitos sendo que dois deles substituem ligações $\alpha J$ e o outro uma ligação $J$.

A diferença entre os dois casos ilustrados (Figs. 6.8 e 6.9) se deve apenas pela mudança de posição de um dos defeitos entre ligações do tipo $J$ e $\alpha J$, resultando em energias distintas, já que o sistema mesmo com ccp não possui invariância translacional.

Tabela 6.2: Caso 2.

\begin{tabular}{|c|c|}
\hline Defeito & Posição \\
\hline \hline$J^{\prime}=0.10 J$ & Ligação $\alpha J$ \\
\hline$J^{\prime \prime}=0.70 J$ & Ligação $J$ \\
\hline$J^{\prime \prime \prime}=0.90 J$ & Ligação $J$ \\
\hline
\end{tabular}




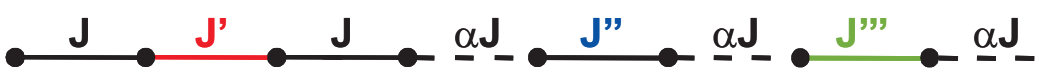

Figura 6.9: Caso 2 - Cadeia com três defeitos sendo que dois deles substituem ligações $J$ e o outro uma ligação $\alpha J$.

Em seqüência mostramos a comparação entre a energia dada pelo funcional e os resultados de diagonalização exata.

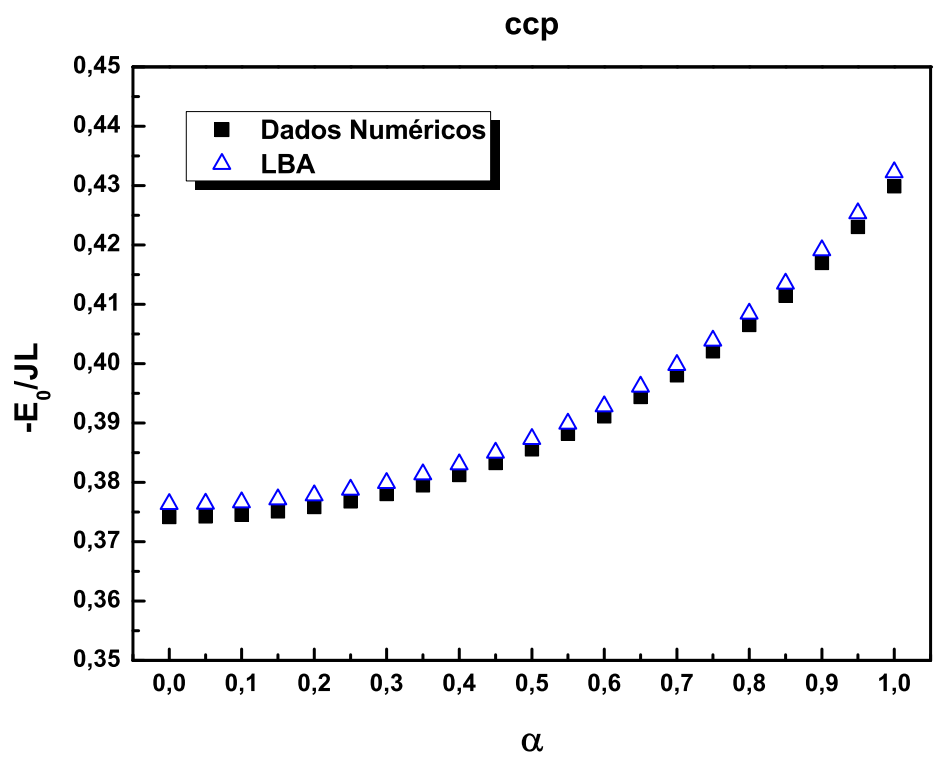

Figura 6.10: Caso 1.

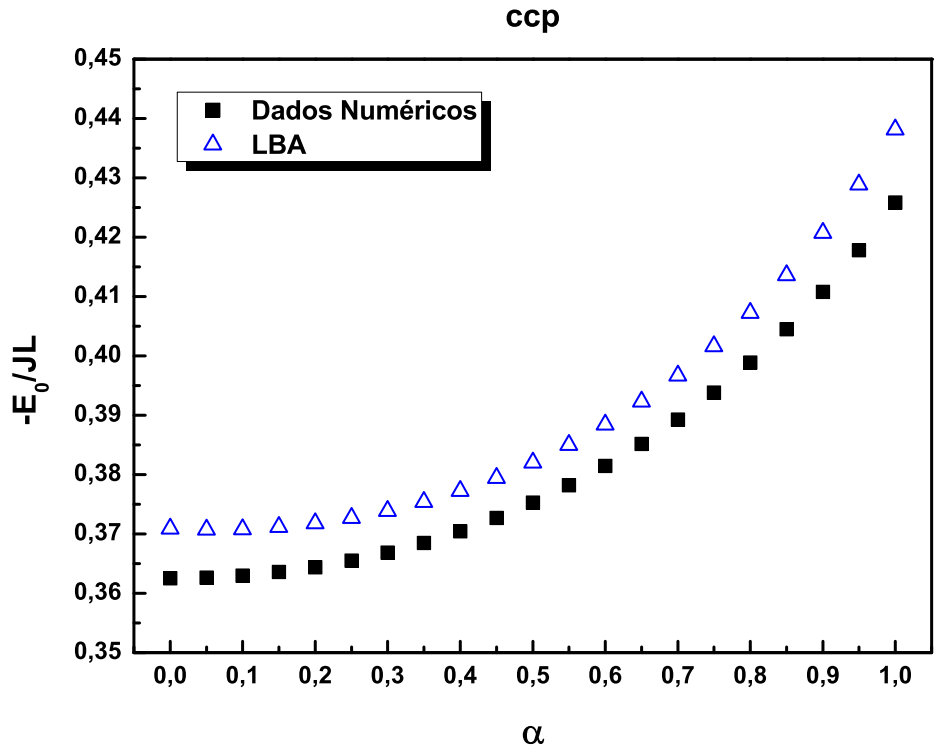

Figura 6.11: Caso 2.

Apesar da aproximação usada na construção do funcional ser local, vemos nos gráficos 
6.10 e 6.11 que ele se comporta melhor no primeiro caso (que lembra o sistema homogêneo inicial - cadeia alternada) e consegue distinguir entre as posições dos defeitos. Isso porque, a aproximação que utilizamos é local em $\alpha_{i}$ e não é local em $J_{i}$. Essa distinção não ocorre para o campo médio e nem para os funcionais da Ref. (17).

\subsection{Relevância da posição dos defeitos na cadeia}

Em uma cadeia uniforme com condição de contorno periódica e somente com um defeito (Fig. 6.5) é irrelevante, do ponto de vista energético, sabermos a localização de tal inomogeneidade. Para o funcional, entretanto, é relevante, mesmo nessa situação, se o defeito se localiza em uma ligação $J$ ou $\alpha J$. E para mostrarmos esse aspecto colocamos um defeito em lugares distintos na rede e comparamos os resultados com os dados numericamente exatos.

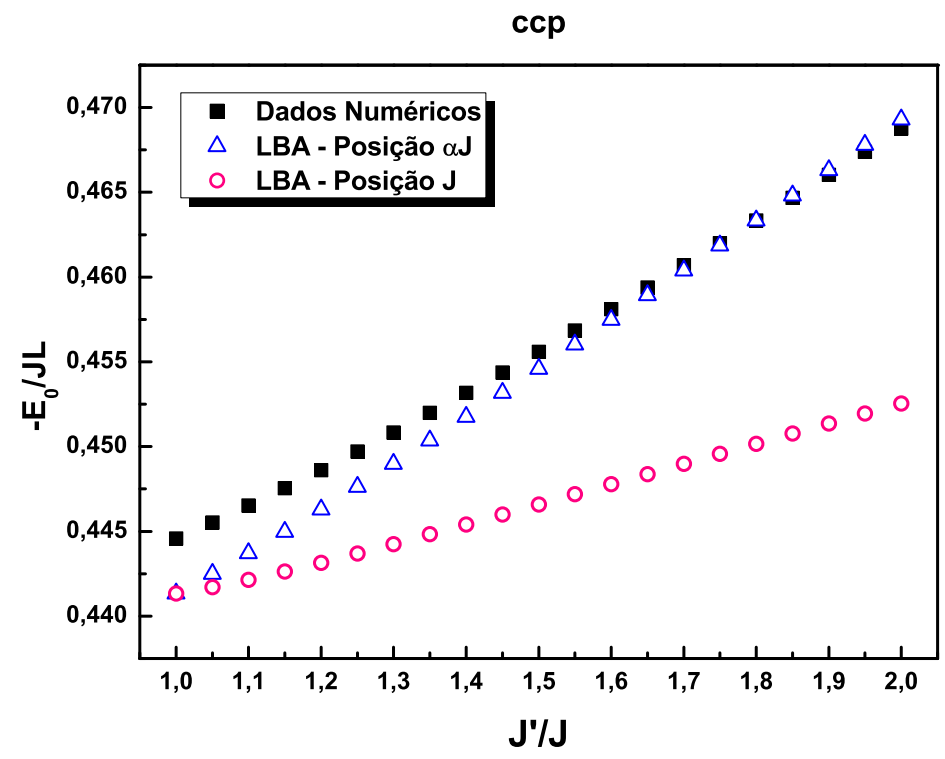

Figura 6.12: Os quadrados em preto representam os dados obtidos por diagonalização exata, os triângulos em azul a LBA para um defeito em uma posição $\alpha J$ e os círculos em rosa a LBA para um defeito em uma ligação $J$.

O funcional representado pelos resultados em rosa não consegue reproduzir os dados exatos quando temos o defeito ocupando uma interação do tipo $J$ (4\% de erro), pelo menos não tão bem quanto nos casos anteriores.

Quando a condição de contorno é aberta, naturalmente há distinção da localização 
de uma ligação diferente. Colocando um defeito $J^{\prime}=0.50 \mathrm{~J}$ em uma cadeia uniforme e variando a sua posição obtemos os resultados mostrados na Fig. 6.13.
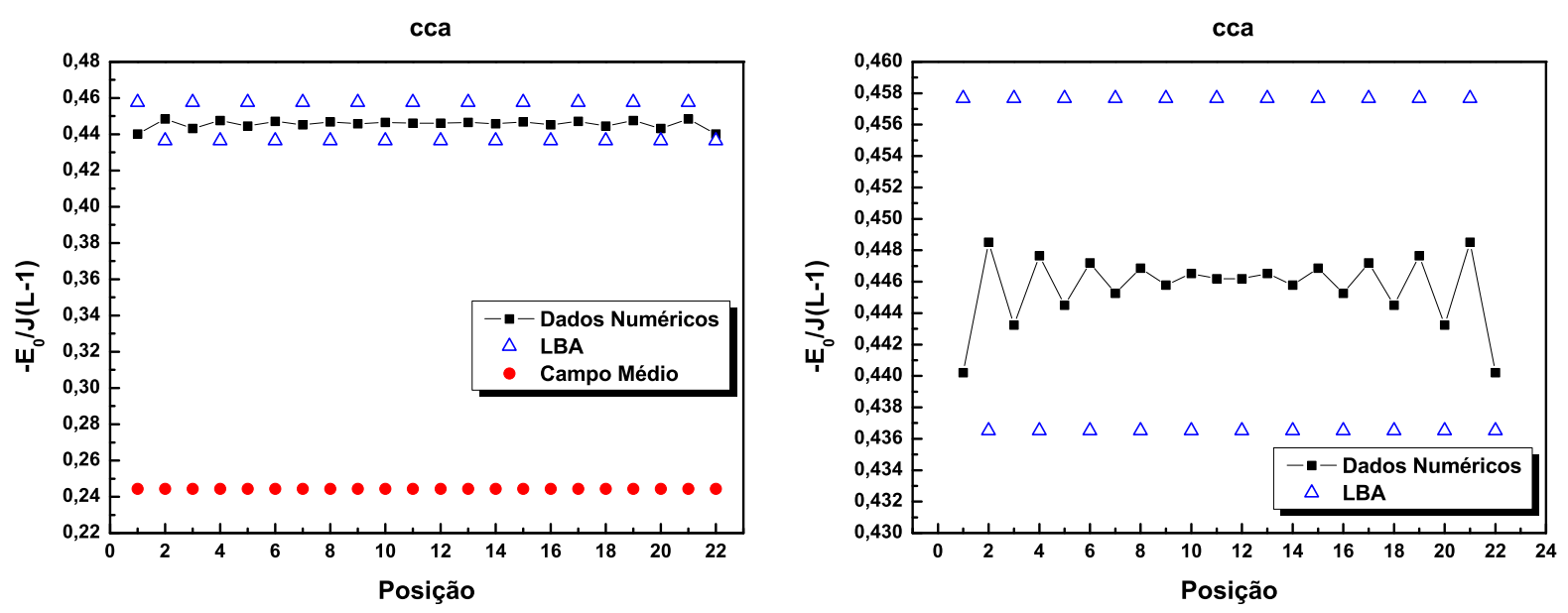

Figura 6.13: Energia de uma cadeia uniforme com um defeito $J^{\prime}=0.50 J$ em função da posição do defeito; à direita temos os dados numéricos exatos e o funcional em uma escala ampliada.

Os dados numericamente exatos representados pelos quadrados em preto refletem na energia a simetria em relação ao centro da cadeia. O funcional só consegue diferenciar entre as posições $n=1,3, \ldots$ e $n=2,4, \cdots$, ou seja, entre posições ímpares e pares, sendo irrelevante se houver troca entre elas (por exemplo $3 \rightarrow 5$ ). Para o campo médio, círculos vermelhos, a posição é indistinguível e a energia é constante. Sendo assim, o funcional apreende, ao menos em parte, a oscilação presente nos dados numericamente exatos.

\subsection{Outros funcionais}

Submetemos o funcional, sujeito a defeitos antiferromagnéticos, a uma última comparação, não apenas com resultados obtidos por diagonalização exata, como também com uma proposta anterior à nossa de contrução de um funcional das ligações Ref. (17).

A proposição se baseia na idéia semelhante a LSA substituindo localmente a interação de cada sítio $\left(J \rightarrow J_{i}\right)$. A LBA é então aplicada utilizando como energia do sistema homogêneo de referência as conhecidas expressões obtidas pela Spin-wave (SW) e pelo Grupo de Renormalização da Matriz Densidade (DMRG). As energias de correlação para 
os dois casos são dadas respectivamente por

$$
E_{C}^{L B A-S W}=\left(\frac{2}{\pi}-1\right) S \sum_{i} J_{i}
$$

$\mathrm{e}$

$$
\begin{aligned}
E_{C}^{L B A-D M R G}= & {\left[\left(\frac{2}{\pi}-1\right) S-0.03262-\frac{0.0030}{S}+\frac{0.0015}{S^{3}}-\right.} \\
& \left.\left(0.338-\frac{0.28}{S}+\frac{0.035}{S^{3}}\right) e^{-\pi S} \cos (2 \pi S)\right] \sum_{i} J_{i}
\end{aligned}
$$

Os gráficos a seguir comparam as energias (em função do tamanho da cadeia) obtidas pelos três funcionais (denominamos a nossa construção apenas por LBA, denotando as outras duas por LBA-SW e LBA-DMRG) com os resultados numericamente exatos para uma situação com um defeito $J^{\prime}=5 J$.
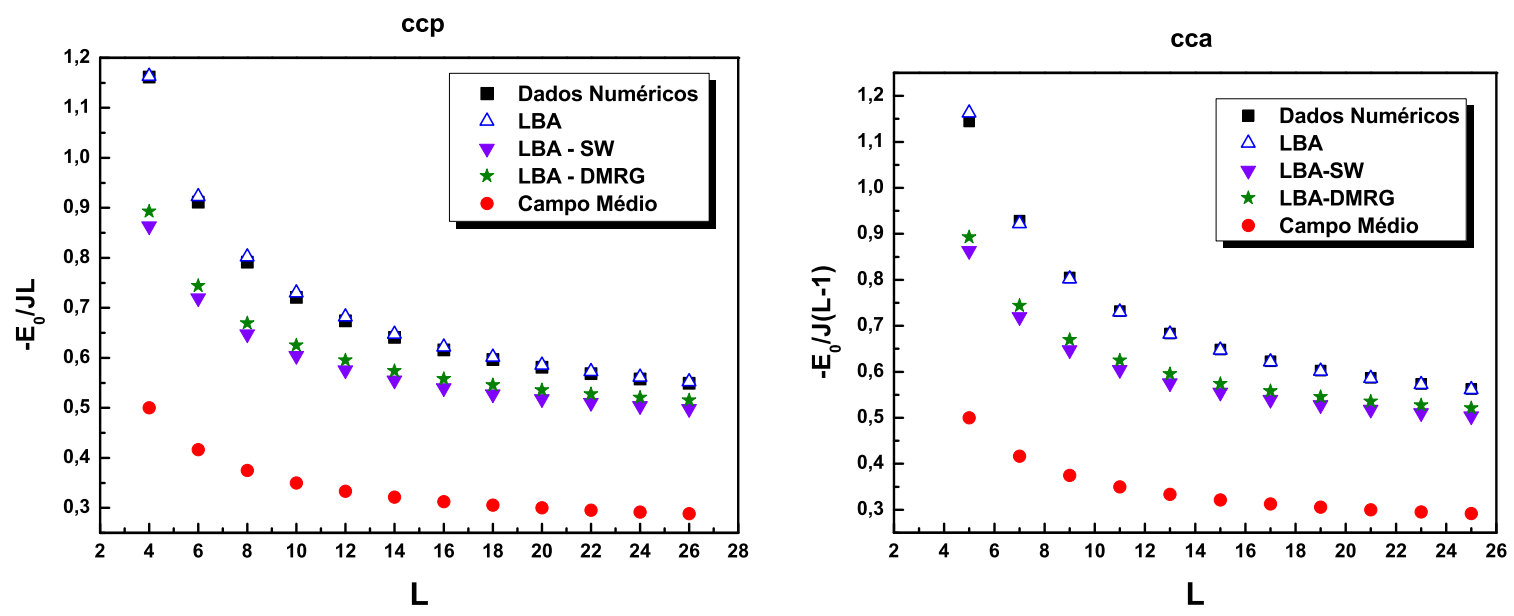

Figura 6.14: Um defeito $J^{\prime}=5 J$ no interior da cadeia.

Na Fig. 6.14 temos ccp (gráfico da esquerda) e cca (gráfico da direita), e a denominação interior significa que colocamos o defeito em uma ligação localizada no meio da cadeia, no caso uma ligação par.

O funcional LBA (triângulos azuis), como já evidenciado reproduz muito bem os dados exatos, sendo uma aproximação melhor para a energia que LBA-SW e LBA-DMRG, mesmo quando a condição de contorno é aberta, pois há dependência com o tamanho da cadeia. Esse comportamento, entretanto, não se repete quando o defeito está na borda 

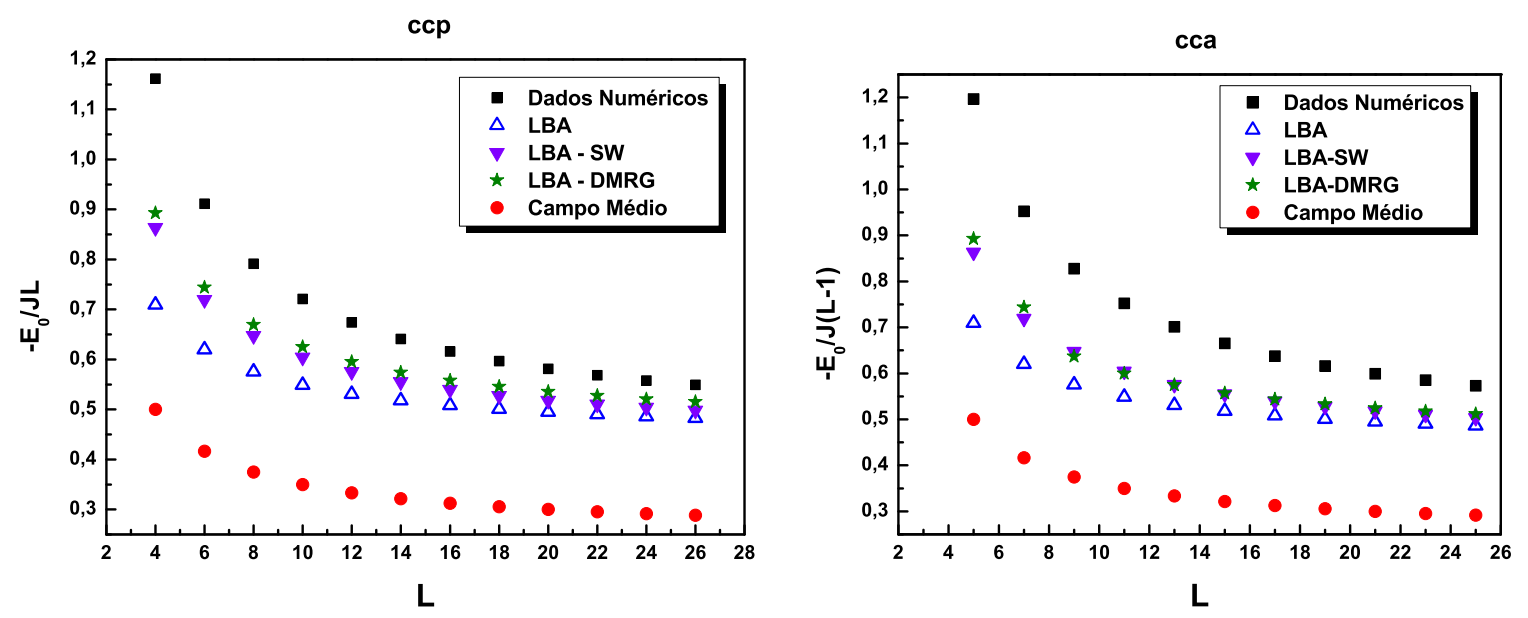

Figura 6.15: Um defeito $J^{\prime}=5 J$ na borda.

(ligação ímpar ou ligação $J$ ) e pode ser verificado na Fig. 6.15. 


\section{Capítulo 7}

\section{Defeitos Ferromagnéticos}

A expressão para $E_{0}\left[\alpha_{i}\right]$ (Eq. (5.8)) é composta por dois termos: o campo médio e a energia de correlação. A energia de campo médio do estado fundamental é obtida minimizando-se as variáveis de spin para uma dada distribuição de ligações $\left(J_{i}\right)$; já a energia de correlação, envolve apenas a razão entre as interações de dois sítios vizinhos e, portanto, somente contribui para que a energia total (campo médio + correlação) seja reduzida. Assim, o termo de campo médio seria o responsável pela minimização da energia total. Nas seções precedentes, em que tratamos apenas sistemas contendo interações antiferromagnéticas, a configuração de mínima energia corresponde àquela em que os spins estão dispostos antiparalelamente. Nas próximas seções veremos como essas configurações mudam na presença de ligações ferromagnéticas.

Neste momento, gostaríamos de lembrar que o funcional foi construído a partir de um sistema homogêneo constituído por uma cadeia antiferromagnética, e por esse motivo não esperamos de antemão que esse se comporte tão bem na presença de defeitos ferromagnéticos quanto se comporta na presença de defeitos antiferromagnéticos.

Devido aos muitos exemplos que podemos construir sobre defeitos ferromagnéticos em cadeias antiferromagnéticas, abordaremos apenas a situação em que temos condição de contorno periódica e número par de sítios $(L)$. 


\subsection{Cadeia uniforme com defeitos ferromagnéticos}

Inserimos defeitos ferromagnéticos $\left(J^{\prime}<0\right)$ em uma cadeia uniforme (Fig. 7.1), isto é, uma cadeia em que todos os sítios eram equivalentes antes da colocação dos defeitos.

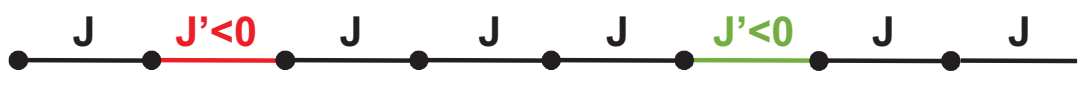

Figura 7.1: Cadeia uniforme com defeitos ferromagnéticos.

Nessa situação, temos que diferenciar dois casos para o cálculo da energia de campo médio: número ímpar e número par de defeitos.

\subsubsection{Número ímpar de defeitos}

A energia na aproximação de campo médio para o estado fundamental é dada por

$$
E_{0}^{C M}=-(L-1) J S^{2}-J^{\prime} S^{2}
$$

enquanto a configuração de spins é

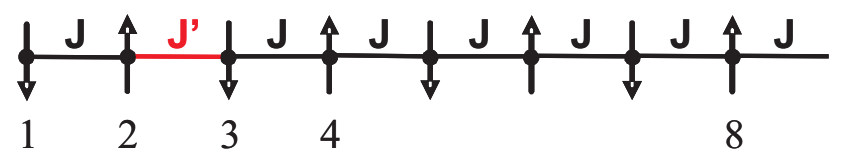

Figura 7.2: Configuração do estado fundamental de uma cadeia uniforme, com $L$ par e condição de contorno periódica com um defeito ferromagnético $\left|J^{\prime}\right|<J$.

A expressão (7.1) somente é válida no caso de $\left|J^{\prime}\right|<J$, e nessa situação observa-se que apesar da ligação ser ferromagnética (favorecendo o alinhamento paralelo dos spins), o sistema prefere manter o alinhamento antiferromagnético entre os spins 2 e 3.

Já no caso da interação ferromagnética ser mais intensa do que a antiferromagnética, isto é $\left|J^{\prime}\right|>J$, há uma mudança no comportamento do sistema, sendo a configuração mais favorável dada por 


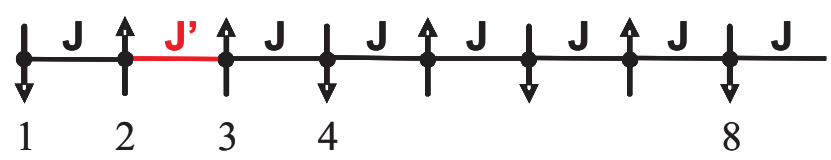

Figura 7.3: Configuração do estado fundamental de uma cadeia uniforme, com $L$ par e condição de contorno periódica com um defeito ferromagnético para $\left|J^{\prime}\right|>J$.

ou seja, os spins 2 e 3 que interagem ferromagneticamente ficam paralelos, e além disso, a ligação (antiferromagnética) entre os spins 1 e 8 é frustrada. A energia de campo médio nessa situação é dada pela expressão

$$
E_{0}^{C M}=-(L-3) J S^{2}+J^{\prime} S^{2}
$$

Abaixo, na Fig. 7.4 mostramos a energia de campo médio, por partícula e em unidades de $J$, em função da razão entre as intensidades das ligações ferromagnética e antiferromagnética, ficando explícita a mudança de comportamento do sistema quando $J^{\prime}=-J$.

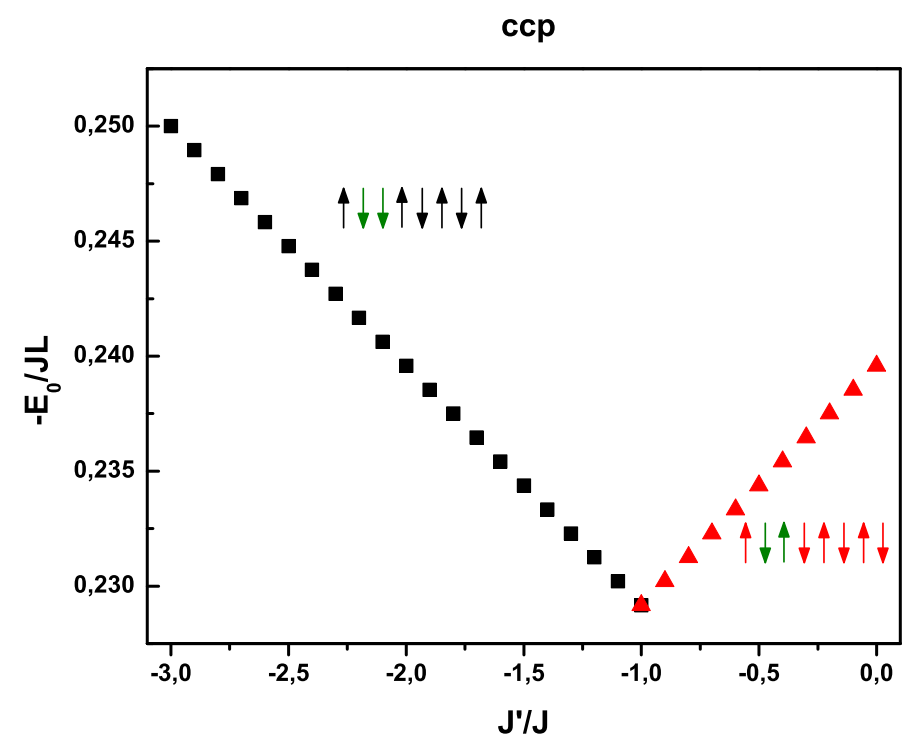

Figura 7.4: Energia de campo médio por ligação e em unidades de $J$ para uma cadeia uniforme com um defeito ferromagnético. Observe o alinhamento dos spins 2 e 3, apesar do sinal de $J^{\prime} / J$.

A seguir (Fig. 7.5), apresentamos uma comparação entre o funcional LBA (triângulos azuis), os resultados numericamente exatos (quadrados pretos) e campo médio (círculos 
vermelhos) (gráfico à esquerda) para $J^{\prime}$ no intervalo $[-1,0]$; à direita temos somente o funcional e os dados numéricos em escala ampliada.
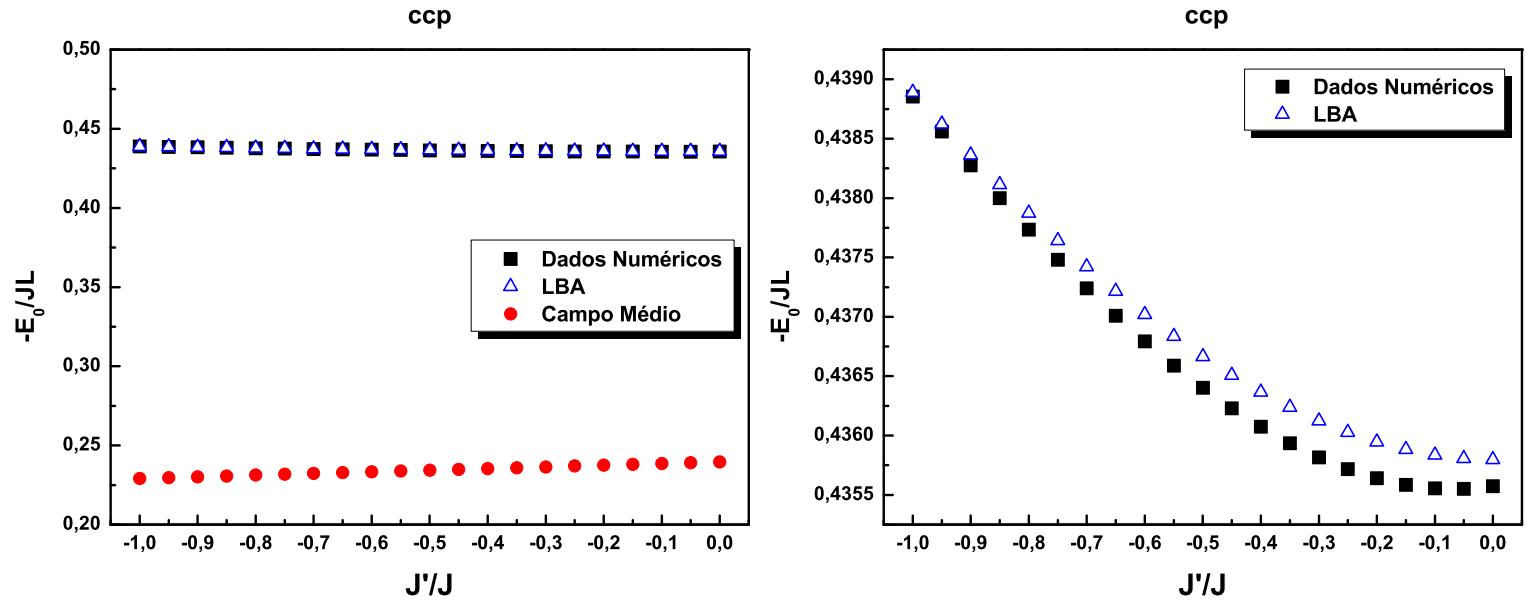

Figura 7.5: Energia do estado fundamental por ligação e em unidades de $J$ para uma cadeia uniforme com um defeito ferromagnético; à direita em escala ampliada.

Notamos que o funcional (5.8) concorda bastante bem com os resultados exatos, sendo a discrepância entre estes menor do que 1\% (observemos a escala do gráfico à direita). Vemos também no gráfico à direita que o funcional "superestima" (em módulo) o valor da energia.

\subsubsection{Número par de defeitos}

Quando inserimos $n$ defeitos ferromagnéticos (desde que $n=2 m$, com $m=0,1, \ldots$ ) em uma cadeia uniforme antiferromagnética, só existe uma configuração para o termo de campo médio que minimiza a energia, tanto para $\left|J^{\prime}\right|<J$ quanto para $\left|J^{\prime}\right|>J$. Em seguida (Fig. 7.6) ilustramos uma cadeia com dois defeitos,

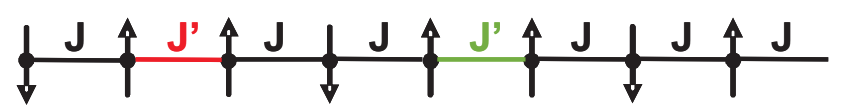

Figura 7.6: Configuração de mínima energia para uma cadeia com dois defeitos ferromagnéticos.

e os resultados (Fig. 7.7) para a energia obtida através do funcional. 


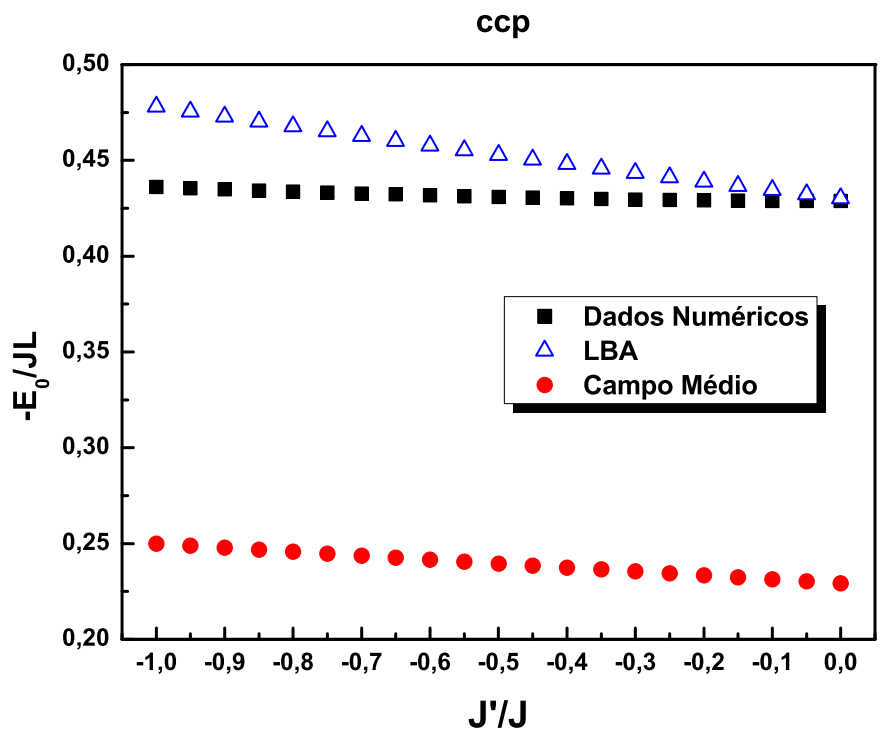

Figura 7.7: Energia do estado fundamental, por ligação e em unidades de $J$, em função da razão $J^{\prime} / J$ para uma cadeia uniforme com dois defeitos ferromagnéticos.

Para um caso geral com $n$ defeitos a energia é dada pela expressão

$$
E_{0}^{C M}=-(L-n) J S^{2}-n J^{\prime} S^{2}
$$

Através dos resultados acima percebemos que o funcional, apesar de apresentar uma melhora substancial em relação ao campo médio, não consegue mais reproduzir tão bem os dados numericamente exatos quando $J^{\prime} \rightarrow J$; o erro na região de $J^{\prime}=-J$ é de aproximadamente $10 \%$.

À medida que acrescentamos defeitos à rede até que se torne uma cadeia com ligações que se alternam entre antiferromagnéticas e ferromagnéticas (Fig. 7.8), retornamos ao sistema homogêneo inicial com a diferença, entretanto, de que originalmente a cadeia só possuía interações antiferromagnéticas.

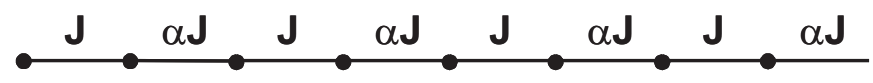

Figura 7.8: Sistema com ligações que se alternam entre antiferromagnéticas e ferromagnéticas, $\alpha<0$.

O gráfico abaixo (Fig. 7.9) mostra a energia em função do parâmetro $\alpha(\alpha<0$ neste caso). 


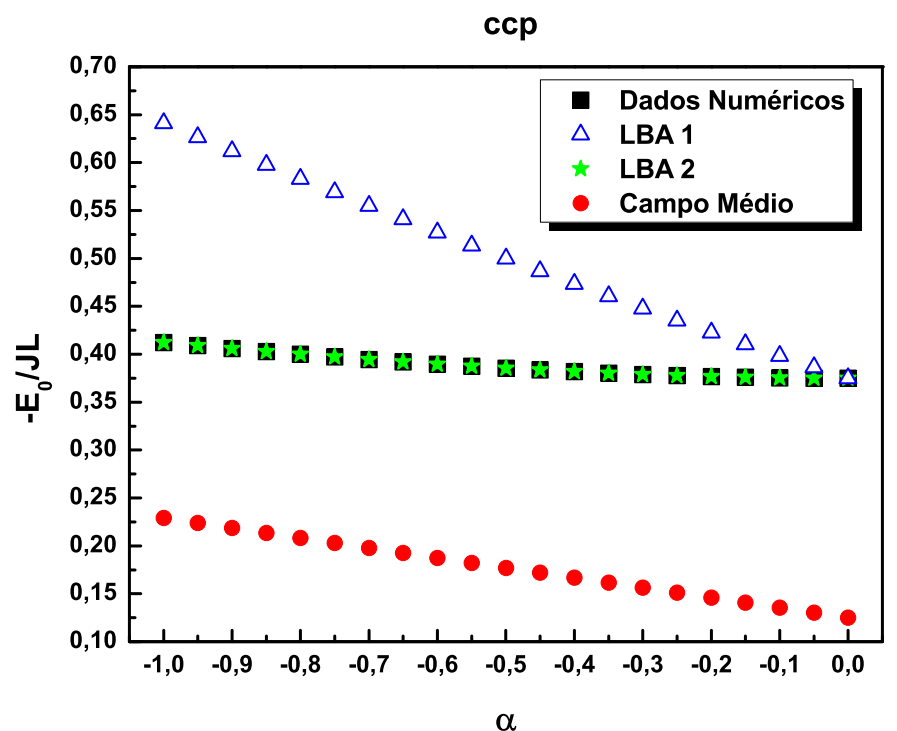

Figura 7.9: Energia do estado fundamental por ligação e em unidades de $J$ para uma cadeia em que as interações se alternam entre antiferromagnéticas e ferromagnéticas.

Os pontos correspondentes a LBA 1 (triângulos azuis) representam os resultados obtidos usando a Eq. (7.3) para energia de campo médio, isto é, a expressão que condiz com a configuração de mínima energia. Já a LBA 2 (estrelas verdes) utiliza o campo médio de uma cadeia em que os spins estão alinhados antiparalelamente mesmo a interação sendo ferromagnética; esta última situação resulta em uma melhor concordância com os dados numericamente exatos.

Temos aqui dois pontos a serem questionados. O primeiro diz respeito à minimização da energia. Como já mencionado, o termo da energia que corresponde à correlação não depende explicitamente das variáveis de spin. No entanto, pelos resultados obtidos concluímos que o funcional como um todo deve ser minimizado e não somente a parte de campo médio. A outra questão se refere ao motivo pelo qual a LBA 2 funciona tão bem. Devemos lembrar neste momento, que o nosso sistema homogêneo inicial constituía-se de uma cadeia alternada antiferromagnética, o que está de acordo com o campo médio na expressão para a LBA 2. Além disso, a aplicação da LBA na energia de correlação considera dímeros, isto é, pares de ligações, tornando-se assim uma aproximação não-local do ponto de vista de cada interação $J_{i}$. A cadeia alternada que estamos tentando reproduzir é uma extrapolação dos limites de validade em que o funcional foi construído. Nessa situação, em particular, a expressão do funcional reduz-se à própria série proposta na Ref. (11), 
extrapolada, no entanto, para ligações ferromagnéticas. Os dois pontos levantados acima nos levam então à conclusão de que para incluir interações ferromagnéticas na classe de resultados muito bem representados pelo funcional, precisaríamos rever a correlação, ou seja, procurar por melhores aproximações para $E_{0}(\alpha)$.

\subsection{Cadeia alternada com defeitos ferromagnéticos}

Vamos considerar agora uma cadeia alternada com parâmetro $\alpha$. Os defeitos podem substituir tanto as ligações do tipo $\alpha J$ quanto as ligações do tipo $J$.

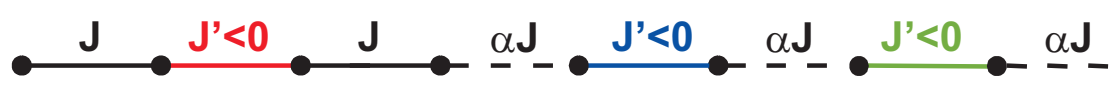

Figura 7.10: Cadeia alternada com defeitos ferromagnéticos.

Como na seção anterior, temos que diferenciar os casos em que há número par e ímpar de defeitos, porém mostraremos apenas os resultados para uma cadeia alternada com um defeito em uma ligação do tipo $\alpha J$.

Para $\left|J^{\prime}\right|>\alpha J$ a energia de campo médio é dada por

$$
E_{0}^{C M}=-\frac{L}{2} J S^{2}-\left(\frac{L}{2}-3\right) \alpha J S^{2}+J^{\prime} S^{2}
$$

enquanto a configuração de spins do estado fundamental é

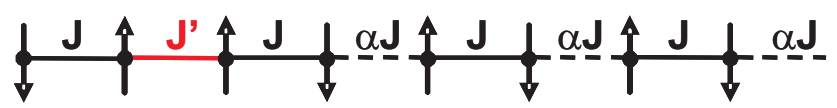

Figura 7.11: Configuração que minimiza a energia de campo médio quando $\left|J^{\prime}\right|>\alpha J$.

No caso de $\left|J^{\prime}\right|<\alpha J$ temos

$$
E_{0}^{C M}=-\frac{L}{2} J S^{2}-\left(\frac{L}{2}-1\right) \alpha J S^{2}-J^{\prime} S^{2}
$$

e a configuração de spins é 


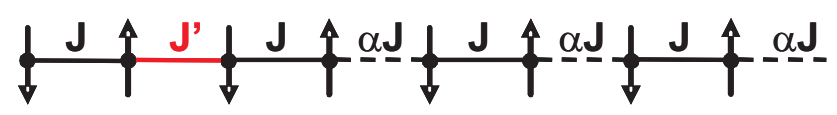

Figura 7.12: Configuração que minimiza a energia de campo médio quando $\left|J^{\prime}\right|<\alpha J$.

Ou ainda, quando o número de defeitos for $n(n=2 m+1$, com $m=0,1, \ldots)$, temos

$$
E_{0}^{C M}=-\frac{L}{2} J S^{2}-\left(\frac{L}{2}-(n+2)\right) \alpha J S^{2}+\sum_{i=1}^{n} J_{i}^{\prime} S^{2} \Rightarrow \alpha J \leq \sum_{i=1}^{n}\left|J_{i}^{\prime}\right|
$$

e

$$
E_{0}^{C M}=-\frac{L}{2} J S^{2}-\left(\frac{L}{2}-n\right) \alpha J S^{2}-\sum_{i=1}^{n} J_{i}^{\prime} S^{2} \Rightarrow \alpha J \geq \sum_{i=1}^{n}\left|J_{i}^{\prime}\right| .
$$

O gráfico a seguir mostra os resultados do funcional para uma cadeia alternada com um defeito ferromagnético $\left(J^{\prime}=-0.80 J\right)$ em função do parâmetro $\alpha$.

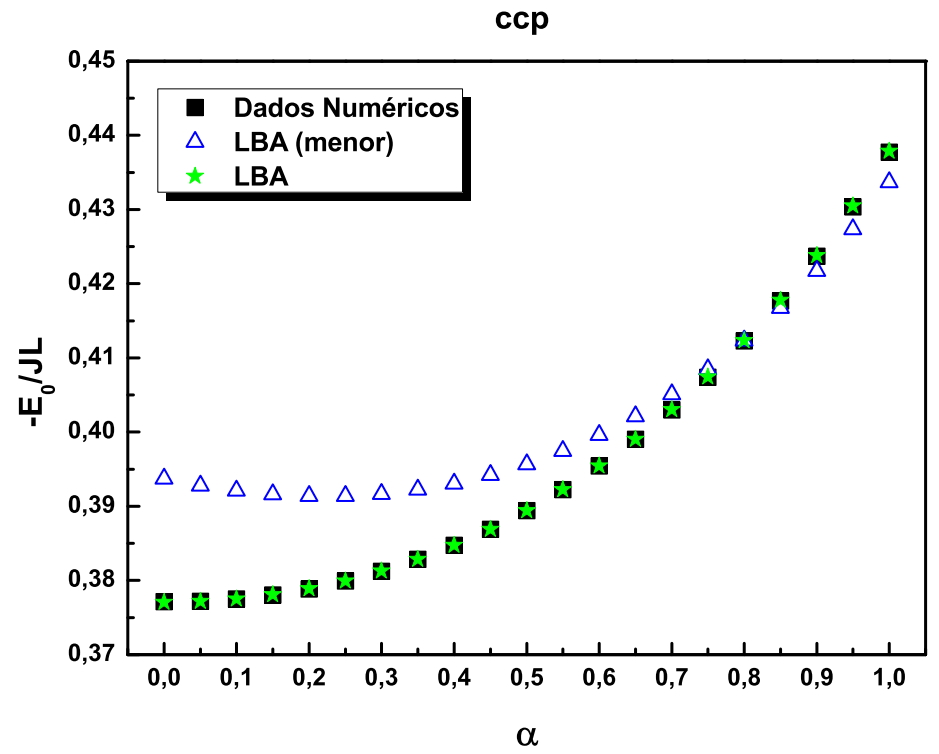

Figura 7.13: Energia do estado fundamental por ligação e em unidades de $J$ para uma cadeia alternada com um defeito ferromagnético substituindo uma ligação $\alpha J, J^{\prime}=-0.80 J$.

Novamente notamos que LBA 1 (calculada usando-se o campo médio fornecido pela Eq. (7.4)) difere dos resultados numéricos exatos $(\approx 5 \%)$ ao contrário da LBA 2 (configuração antiferromagnética) que se ajusta muito bem $(\approx 0,5 \%)$ aos dados. 


\subsection{Cadeia com ligações alternando entre ferromagnéticas e antiferromagnéticas}

Essa situação é distinta daquela que consideramos até agora (ligações alternando entre antiferromagnéticas - ferromagnéticas), pois apesar do funcional só depender da razão entre as ligações, quando $\alpha \rightarrow 0$ os dois casos são muito diferentes. Um deles possui dímeros ferromagnéticos e o outro antiferromagnéticos, que obviamente têm energias diferentes.

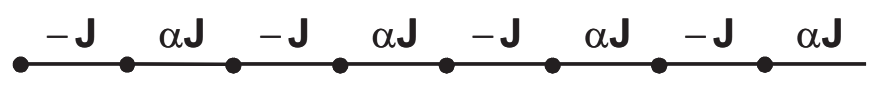

Figura 7.14: Sistema com ligações que se alternam entre ferromagnéticas e antiferromagnéticas.

Assim, levando-se em conta esses dois limites, propusemos uma correção simples na expressão da Ref. (11) para que a situação mostrada na figura (Fig. 7.14) acima também pudesse ser explorada.

Como o Hamiltoniano do problema é essencialmente o mesmo, e para um dímero ferromagnético resulta na energia por partícula $e_{0}=-\frac{1}{8}$, somente trocamos o termo constante $e_{0}(\alpha=0)=-\frac{3}{8}$ na expressão (4.13) (energia por partícula do dímero antiferromagnético) por $e_{0}(\alpha=0)=-\frac{1}{8}$. Portanto, a expressão para $e_{0}$ é dada por

$$
e_{0}(\alpha)=-\frac{1}{8}+f(\alpha)
$$

com $f(\alpha)$ dada pela Eq. (4.14).

Para então construir um novo funcional calculamos a energia de campo médio e a correlação do sistema homogêneo (Fig. 7.14), dadas respectivamente por

$$
E_{0}^{C M}(\alpha)=\frac{L(-J)}{8}-\frac{\alpha J}{4} \frac{L}{2}
$$




$$
E_{\text {hom }}^{C}(\alpha)=J L\left(\frac{1}{8} \alpha+f(\alpha)\right)
$$

com $J>0$ e $\alpha>0$. E portanto, a expressão para o funcional na aproximação LBA (5.5) é dada por

$$
E^{L B A}\left[\alpha_{i}\right]=J \sum_{i=1}^{L} \alpha_{i} \vec{S}_{i} \cdot \vec{S}_{i+1}+J \sum_{i=1}^{N_{d}} 2\left(\frac{1}{8} \alpha_{i}+f\left(\alpha_{i}\right)\right) .
$$

O gráfico a seguir mostra os resultados para um sistema em que as ligações se alternam entre ferromagnéticas e antiferromagnéticas.

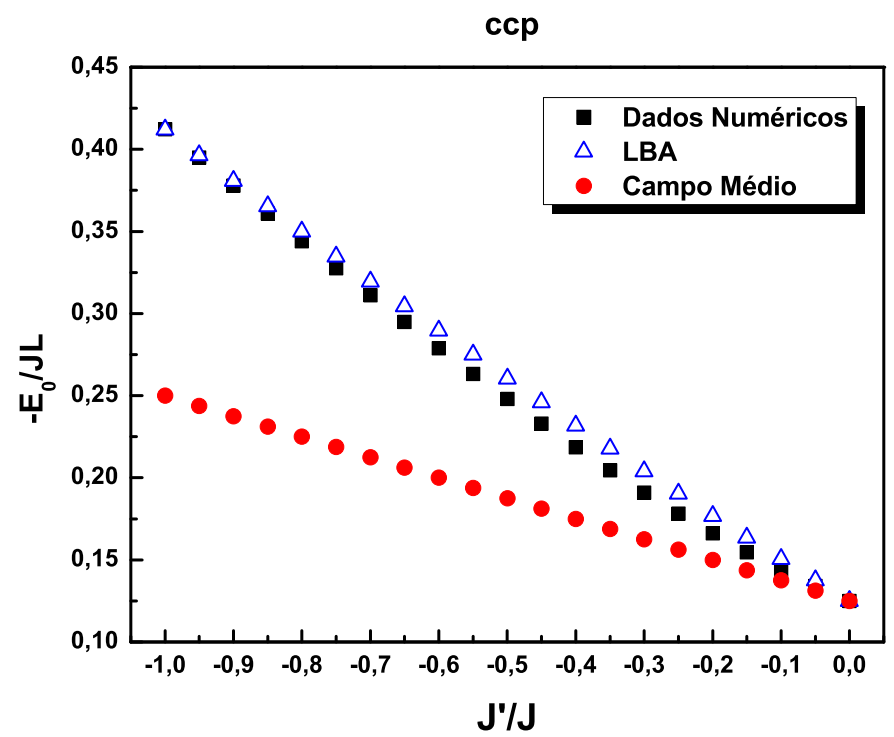

Figura 7.15: Energia do estado fundamental por ligação e em unidades de $J$ para uma cadeia em que as ligações se alternam entre ferromagnéticas e antiferromagnéticas.

Observamos que os resultados fornecidos pelo funcional (7.11), apesar da simples alteração que fizemos na expressão (4.13), reproduz muito bem os dados numéricos exatos, inclusive no limite em que $\alpha \rightarrow 0$ onde a aproximação de campo médio é melhor (para $\alpha=0$ é exata e a correlação deve ser nula). 


\section{Capítulo 8}

\section{Conclusões}

No presente trabalho estudamos cadeias antiferromagnéticas de spins $1 / 2$ descritas pelo Hamiltoniano de Heisenberg na presença de inomogeneidades. Especificamente, nosso objetivo era a determinação da energia do estado fundamental de sistemas nos quais as inomogeneidades fossem causadas por ligações substitucionais, isto é, defeitos na interação de troca spin-spin. Para essa finalidade, utilizamos como ferramenta o formalismo da Teoria do Funcional da Densidade (DFT) desenvolvida para o modelo de Heisenberg, aplicando a aproximação da ligação local (LBA) para a construção de funcionais.

A nossa proposição de construção de um funcional das ligações se baseou em um sistema constituído por uma cadeia alternada antiferromagnética, na qual as ligações se alternam entre dois valores $(J$ e $\alpha J)$. A aplicação da LBA resultou em um funcional da razão entre duas interações vizinhas; na verdade obtivemos dois funcionais válidos em limites distintos.

Inicialmente tratamos de cadeias com defeitos antiferromagnéticos, abordando tanto condição de contorno periódica quanto condição de contorno aberta. Nessas situações os funcionais apresentaram um bom desempenho, principalmente em relação à energia de campo médio, reproduzindo com considerável precisão os resultados exatos. Além disso, a aproximação, apesar do nome LBA, resultou em funcionais não-locais, possibilitando que estes descrevessem também os casos em que o defeito é trocado de posição.

Devido ao êxito obtido pelos funcionais na descrição de sistemas com defeitos antiferromagnéticos, nosso passo seguinte foi tentar estender a aplicabilidade desses a defeitos 
ferromagnéticos. Os resultados para essa situação, entretanto, não se mostraram tão acurados e revelam a necessidade de se procurar por melhores aproximações (além da LBA) para a construção de um funcional.

Nossa última análise consistiu na tentativa de descrever uma cadeia em que as ligações se alternam entre ferromagnéticas e antiferromagnéticas. Para isso, propusemos uma pequena modificação na energia do sistema que utilizamos na construção do funcional. O resultado obtido está de acordo com os dados exatos e reproduz até mesmo o limite em que a cadeia se compõe apenas de dímeros ferromagnéticos, onde a energia de campo médio é exata.

De um modo geral, a implementação por nós apresentada com base na LBA originou funcionais capazes de descrever bastante bem sistemas com defeitos substitucionais nas ligações, principalmente defeitos antiferromagnéticos. Há, no entanto, necessidade de procurar por novos funcionais que sejam válidos para quaisquer spins $S$ e também em dimensões mais altas. A teoria de Spin-wave (SW) fornece condições de se construir funcionais para qualquer $S$ e em 1, 2 e 3 dimensões, mas apenas para interações uniformes, e assim, não pode estimar a energia do estado fundamental de sistemas mais realistas em que defeitos são inevitáveis ou até desejáveis. 


\section{Referências}

1 HEISENBERG, W. Mehrköperproblem und Resonanz in der Quantenmechanik. Zeitschrift für Physik, v. 38, p. 411-426, 1926.

2 HEISENBERG, W. Zur theorie des ferromagnetismus. Zeitschrift für Physik, v. 49, n. 559, p. 619-636, 1928.

3 DAI, D.; WHANGBO, M.-H. Spin exchange interaction of a spin dimer: analysis of broken-symmetry spin states in terms of the eigenstates of Heisenberg and Ising spin Hamiltonians. Journal of Chemical Physics, v. 118, n. 1, p. 29-39, 2003.

4 TCHOUGREEFF, A. L. Heisenberg Hamiltonian for charge-transfer organometallic ferromagnets. Journal of Chemical Physics, v. 96, n. 8, p. 6026-6032, 1992.

5 BETHE, H. Zur theorie der metalle. Zeitschrift für Physik A: hadrons and nuclei, v. 71, n. 3-4, p. 205-226, 1931.

6 HULthÉN, L. Über das austauschproblem eines kristalles. Arkiv för Matematik, Astronomi och Fysik, v. 26A, n. 1, p. 105, 1938.

7 ANDERSON, P. W. An approximate quantum theory of the antiferromagnetic ground state. Physical Review, v. 86, n. 5, p. 694-701, 1952.

8 LOU, J. et al. Topological effects in short antiferromagnetic Heisenberg chains. Physical Review B, v. 65, n. 10, p. 104401, 2002.

9 LÍBERO, V. L.; CAPELLE, K. Spin-distribution functionals and correlation energy in the Heisenberg model. Physical Review B, v. 68, n. 2, p. 024423, 2003.

10 ASSIS, P. E. G.; LÍBERO, V. L.; CAPELLE, K. Impurity and boundary effects in one and two-dimensional inhomogeneous Heisenberg antiferromagnets. Physical Review B, v. 71, n. 5, p. 052402, 2005.

11 BARNES, T.; RIERA, J.; TENNANT, D. A. $S=1 / 2$ alternating chain using multiprecision methods. Physical Review B, v. 59, n. 17, p. 11384-11397, 1999.

12 WEISS, P. L'hypothése du champ moléculaire et la propriété ferromagnétique. Journal de Physique Théorique et Appliquée, v. 6, p. 661, 1907.

13 ASHCROFT, N. W.; MERMIN, N. D. Solid state physics. New York: Holt, Rinehart and Winston, 1976.

14 SMART, J. S. Effective field theories of magnetism. Philadelphia: W. B. Saunders Company, 1966. 
15 DIRAC, P. A. M. On the theory of quantum mechanics. Proceedings of the Royal Society of London. Series A, v. 112, n. 762, p. 661-677, 1926.

16 HOHENBERG, P.; KOHN, W. Inhomogeneous electron gas. Physical Review, v. 136, n. 3B, p. 864-871, 1964.

17 FÁVARO, A. P. Energia do estado fundamental no modelo de Heisenberg para cadeias de spin com ligações alternadas e com defeitos locais. 2007. 95 p. Dissertação (Mestrado em Física) - Instituto de Física de São Carlos, Universidade de São Paulo, São Carlos, 2007.

18 NORDIO, P. L.; SOOS, Z. G.; MCCONNELL, H. M. Spin excitations in ionic molecular crystals. Annual Review of Physical Chemistry, v. 17, p. 237-260, 1966.

19 NISHI, M.; FUJITA, O.; AKIMITSU, J. Neutron-scattering study on the spin-Peierls transition in a quasi-one-dimensional magnet $C u G e O 3$. Physical Review B, v. 50, n. 9, p. 6508-6510, 1994.

20 LIEB, E.; MATTIS, D. Ordering energy levels of interacting spins systems. Journal of Mathematical Physics, v. 3, n. 4, p. 749-751, 1962. 


\section{Apêndice A}

\section{Método de Potências}

O método de potências sucessivas do Hamiltoniano é usado na determinação do seu menor autovalor. No caso do modelo de Heisenberg, o Hamiltoniano é Hermitiano e representado por uma matriz simétrica cujos autovalores são reais e os autovetores ortogonais (podem ser ortogonalizados). O menor autovalor corresponde à energia do estado fundamental.

O método consiste em propor um estado tentativa,

$$
\left|\Psi_{T}\right\rangle=\sum_{n} \alpha_{n}\left|\varphi_{n}\right\rangle
$$

escrito como combinação linear dos autovetores do Hamiltoniano do sistema, e portanto temos que

$$
\hat{H}\left|\Psi_{T}\right\rangle=\sum_{n} \alpha_{n} E_{n}\left|\varphi_{n}\right\rangle
$$

Aplicando-se à Eq. (1) o Hamiltoniano $k$ vezes obtemos

$$
\hat{H}^{k}\left|\Psi_{T}\right\rangle=\sum_{n} \alpha_{n} E_{n}^{k}\left|\varphi_{n}\right\rangle
$$

Seja $E_{m}$ o maior autovalor (em módulo) de $\hat{H}$. No limite em que $k \rightarrow \infty$ temos

$$
\lim _{k \rightarrow \infty} \hat{H}^{k}\left|\Psi_{T}\right\rangle \cong \alpha_{m} E_{m}^{k}\left|\varphi_{m}\right\rangle
$$


ou seja, o maior autovalor domina na série.

Consideremos então um autovetor $|\phi\rangle$ não ortogonal a $\left|\varphi_{m}\right\rangle$ de modo que

$$
\left\langle\phi|\hat{H}| \Psi_{T}\right\rangle \cong \alpha_{m} E_{m}^{k}\left\langle\phi \mid \varphi_{m}\right\rangle, \quad k \rightarrow \infty
$$

Assim, o maior autovalor de $\hat{H}$ é obtido por

$$
E_{m} \cong \lim _{k \rightarrow \infty} \frac{\left\langle\phi\left|\hat{H}^{k+1}\right| \Psi_{T}\right\rangle}{\left\langle\phi\left|\hat{H}^{k}\right| \Psi_{T}\right\rangle}
$$

\section{Observações}

1. Na realidade queremos o menor autovalor, que é fornecido pelo método subtraindose da diagonal da matriz de $\hat{H}$ uma constante que seja maior que o autovalor mais alto. Essa constante pode ser por exemplo, a energia do estado fundamental da cadeia ferromagnética.

2. O estado tentativa que foi utilizado no programa é o vetor obtido em cada iteração anterior, isto é, no $k$-ésimo passo usamos $|\phi\rangle=H^{k-1}\left|\Psi_{T}\right\rangle$ (devidamente normalizado). Como $H^{k}\left|\Psi_{T}\right\rangle$ se parece cada vez mais com $\left|\varphi_{m}\right\rangle$, o processo de obtenção do autovalor é acelerado. Na primeira iteração $\left|\Psi_{T}\right\rangle$ corresponde ao estado de Néel.

A vantagem do método em relação à diagonalização usual está no fato de que a cada iteração apenas um produto matriz-vetor é realizado. Isso pode ser explorado quando a matriz de $\hat{H}$ é muito grande. Por exemplo, no caso de uma cadeia unidimensional com 20 spins $\frac{1}{2}$, o subespaço a ser diagonalizado possui dimensão 184.756, enquanto que para 24 spins $\frac{1}{2}$ esse número cresce para 2.704.156, tornando inviável a utilização de qualquer método usual de diagonalização. 


\section{Apêndice B}

\section{Teorema de Hohenberg-Kohn para o}

\section{modelo de Heisenberg}

Para demonstrar a validade do teorema para o modelo de Heisenberg deve-se primeiramente estabelecer qual é a variável fundamental do sistema. Na referência (9) propõe-se que essa variável seja $\vec{S}_{i}$, isto é, o valor esperado do spin em cada sítio.

Mostra-se que o teorema é válido para um Hamiltoniano generalizado,

$$
\hat{H}=\sum_{i j} J_{i j} \hat{\mathbf{S}}_{\mathbf{i}} \cdot \hat{\mathbf{S}}_{\mathbf{j}}+\sum_{i} \hat{\mathbf{S}}_{\mathbf{i}} \cdot \mathbf{B}_{i}
$$

ou seja, a soma do primeiro termo no membro da direita não se restringe apenas a primeiros vizinhos e a distribuição das interações $J_{i j}$ é qualquer.

A demostração segue as linhas gerais da Ref. (9).

Consideremos dois Hamiltonianos com a mesma distribuição $J_{i j}$, mas submetidos a campos magnéticos diferentes, $\mathbf{B}$ e $\mathbf{B}^{\prime}$,

$$
\begin{gathered}
\hat{H} \Psi=\left[\sum_{i j} J_{i j} \hat{\mathbf{S}}_{\mathbf{i}} \cdot \hat{\mathbf{S}}_{\mathbf{j}}+\sum_{i} \hat{\mathbf{S}}_{\mathbf{i}} \cdot \mathbf{B}_{i}\right] \Psi=E_{0} \Psi \\
\hat{H}^{\prime} \Psi^{\prime}=\left[\sum_{i j} J_{i j} \hat{\mathbf{S}}_{\mathbf{i}} \cdot \hat{\mathbf{S}}_{\mathbf{j}}+\sum_{i} \hat{\mathbf{S}}_{\mathbf{i}} \cdot \mathbf{B}_{i}^{\prime}\right] \Psi^{\prime}=E_{0}^{\prime} \Psi^{\prime} .
\end{gathered}
$$


$E_{0}$ e $E_{0}^{\prime}$ são as energias do estado fundamental de $\hat{H}$ e $\hat{H}^{\prime}$ respectivamente, e $\Psi$ e $\Psi^{\prime}$ correspondem às funções de onda desses estados.

Supondo que $\hat{H}$ é não-degenerado, pelo princípio variacional temos

$$
E_{0}=\langle\Psi|\hat{H}| \Psi\rangle<\left\langle\Psi^{\prime}|\hat{H}| \Psi^{\prime}\right\rangle
$$

Somando e subtraindo o termo $\sum_{i} \hat{\mathbf{S}}_{\mathbf{i}} \cdot \mathbf{B}_{i}^{\prime}$ à desigualdade (10) obtemos

$$
E_{0}=\langle\Psi|\hat{H}| \Psi\rangle\left\langle\left\langle\Psi^{\prime}\left|\hat{H}^{\prime}\right| \Psi^{\prime}\right\rangle+\sum_{i}\left\langle\Psi^{\prime}\left|\hat{\mathbf{S}}_{i} \cdot\left(\mathbf{B}_{i}-\mathbf{B}_{i}^{\prime}\right)\right| \Psi^{\prime}\right\rangle\right.
$$

que, levando em conta as abreviações $\Delta \mathbf{B}_{i}=\mathbf{B}_{i}-\mathbf{B}_{i}^{\prime}, \mathbf{S}_{i}=\left\langle\Psi\left|\hat{\mathbf{S}}_{\mathbf{i}}\right| \Psi\right\rangle$ e $\mathbf{S}_{i}^{\prime}=\left\langle\Psi^{\prime}\left|\hat{\mathbf{S}}_{\mathbf{i}}\right| \Psi^{\prime}\right\rangle$, pode ser reescrita como

$$
E_{0}<E_{0}^{\prime}+\sum_{i} \mathbf{S}_{\mathbf{i}}^{\prime} \cdot \Delta \mathbf{B}_{i}
$$

Repetindo o procedimento acima para $\hat{H}^{\prime}$ temos

$$
E_{0}^{\prime}<E_{0}-\sum_{i} \mathbf{S}_{\mathbf{i}} \cdot \Delta \mathbf{B}_{i}
$$

A soma das Eqs. (12) e (13) resulta em

$$
E_{0}+E_{0}^{\prime}<E_{0}+E_{0}^{\prime}+\sum_{i}\left(\mathbf{S}_{i}^{\prime}-\mathbf{S}_{i}\right) \cdot \Delta \mathbf{B}_{i}
$$

Se assumirmos que $\left\{\mathbf{S}_{i}\right\}=\left\{\mathbf{S}_{i}^{\prime}\right\}$, isto é, que as duas distribuições de spins correspondentes às funções de onda distintas $\Psi$ e $\Psi^{\prime}$ são iguais, chegamos à contradição

$$
E_{0}+E_{0}^{\prime}<E_{0}+E_{0}
$$

Essa contradição mostra que dois estados fundamentais diferentes não-degenerados não podem dar origem à mesma distribuição de spins. Tem-se que a função de onda correspondente ao estado fundamental é univocamente determinada pela distribuição de spins. 
Assim, o teorema de Hohenberg-Kohn para o modelo de Heisenberg estabelece que a função de onda é um funcional da distribuição de spins, $\Psi=\Psi\left[\mathbf{S}_{i}\right]$. É importante ressaltar que o teorema vale para quaisquer $J_{i j}$.

Uma conseqüência do teorema é que o valor esperado no estado fundamental de qualquer observável $\hat{O}$ também é um funcional de $\mathbf{S}_{i}$

$$
O\left[\mathbf{S}_{i}\right]=\left\langle\Psi\left[\mathbf{S}_{i}\right]|\hat{O}| \Psi\left[\mathbf{S}_{i}\right]\right\rangle
$$

e em particular, a própria energia

$$
E_{0}\left[\mathbf{S}_{i}\right]=\left\langle\Psi\left[\mathbf{S}_{i}\right]|\hat{H}| \Psi\left[\mathbf{S}_{i}\right]\right\rangle .
$$

